ADERSON M. VIANA NETO JULYANNA C. MACIEL LAIS D. FERREIRA ROBERTA R. FURTADO SAMUEL VICTOR DE A. VERAS

\title{
NA PONTA DO LÁPIS: CUSTOS DE PRODUÇĀO
PARA AGROPECUÁRIA CUSTOS DE PRODUÇĀO
PARA AGROPECUÁRIA
}

$-2$
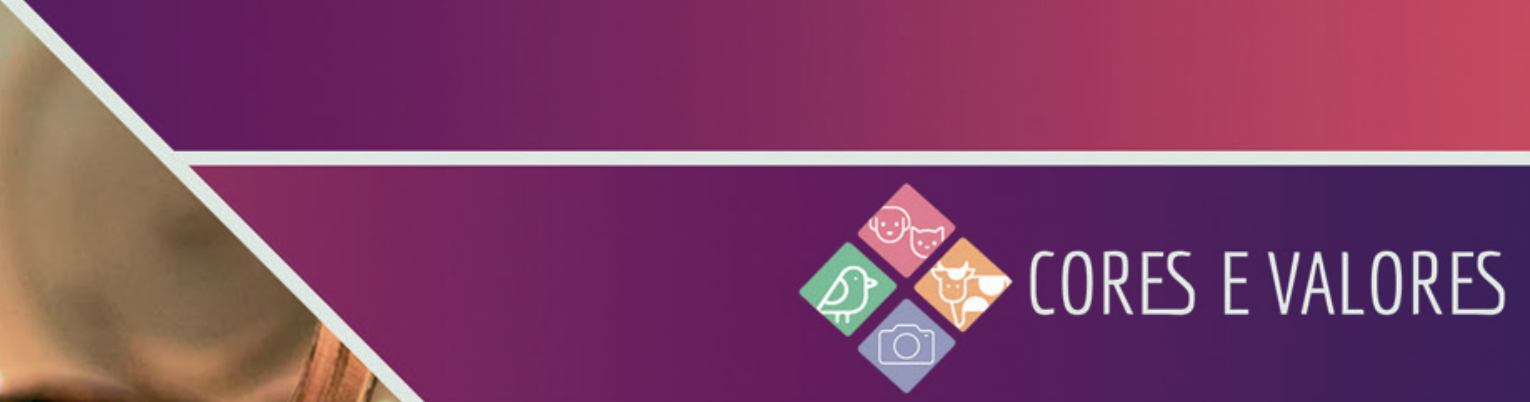

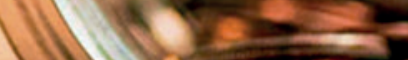

20

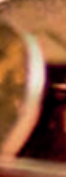

. 
ADERSON M. VIANA NETO JULYANNA C. MACIEL LAÍS D. FERREIRA ROBERTA R. FURTADO SAMUEL VICTOR DE A. VERAS

\section{NA PONTA DO LÁPIS: CUSTOS DE PRODUÇĀO
PARA AGROPECUÁRIA CUSTOS DE PRODUÇĀO
PARA AGROPECUÁRIA}

\section{S. CORES EVALORES}




\author{
2021 by Editora In Vivo \\ Copyright (C) Editora In Vivo \\ Copyright do Texto (C) 2021 O autor \\ Copyright da Edição C 2021 Editora In Vivo
}

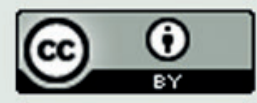

Esta obra está licenciada com uma Licença Creative Commons Atribuição 4.0 Internacional (CC BY 4.0).

O conteúdo desta obra e seus dados em sua forma, correção e confiabilidade são de responsabilidade exclusiva dos autores. Permitido o download da obra e o compartilhamento desde que sejam atribuídos créditos aos autores, mas sem a possibilidade de alterá-la de nenhuma forma ou utilizá-la para fins comerciais.

\title{
Editor Chefe
}

Dr. Everton Nogueira Silva

\section{Conselho Editorial}

1 Colégio de Ciências da Vida

\subsection{Ciências Agrárias}

Dr. Aderson Martins Viana Neto

Dra. Ana Paula Bezerra de Araújo

MSc. Edson Rômulo de Sousa Santos

Dr. Fágner Cavalcante P. dos Santos

MSc. Filomena Nádia Rodrigues Bezerra

Dra. Lina Raquel Santos Araújo

Dr. Luis de França Camboim Neto

MSc. Maria Emília Bezerra de Araújo

MSc. Yuri Lopes Silva

\subsection{Ciências Biológicas}

Dra. Antonia Moemia Lúcia Rodrigues Portela

1.3 Ciências da Saúde

Dra. Ana Luiza Malhado C. de Souza Velho

Dr. Isaac Neto Goes Silva

Dra. Maria Verônyca Coelho Melo

MSc. Paulo Abílio Varella Lisboa

Dra. Vanessa Porto Machado

Dr. Victor Hugo Vieira Rodrigues
2 Colégio de Humanidades

2.1 Ciências Humanas

Dra. Alexsandra Maria Sousa Silva

MSc. Francisco Brandão Aguiar

MSc. Julyana Alves Sales

2.2 Ciências Sociais Aplicadas

MSc. Cícero Francisco de Lima

MSc. Erivelton de Souza Nunes

Dra. Maria de Jesus Gomes de Lima

MSc. Maria Rosa Dionísio Almeida

MSc. Marisa Guilherme da Frota

3 Colégio de Ciências Exatas, Tecnológica

e Multidisciplinar

3.1 Ciências Exatas e da Terra

MSc. Francisco Odécio Sales

Dra. Irvila Ricarte de Oliveira Maia

3.2 Engenharias

MSc. Amâncio da Cruz Filgueira Filho

MSc. Gilberto Alves da Silva Neto

MSc. Henrique Nogueira Silva

Dr. João Marcus Pereira Lima e Silva

MSc. Ricardo Leandro Santos Araújo

Dados Internacionais de Catalogação na Publicação - CIP

V614n Viana Neto, Aderson Martins.

Na ponta do lápis [cartilha eletrônica]: custos de produção para agropecuária. / Aderson M. Viana

Neto... [et al.]. Fortaleza: Editora In Vivo, 2021.

$44 \mathrm{p}$.

Bibliografia.

ISBN: 978-65-993899-3-1

DOI: $10.47242 / 978-65-993899-3-1$

1. Agropecuária. 2. Agropecuária - custos de produção. 3. Grupo Cores e Valores. I. Título. 
As atividades agropecuárias a cada dia exigem uma maior profissionalização dos seus gestores no campo, como forma de otimizar a produção e consequentemente a lucratividade nas mais diversas cadeias produtivas. A profissionalização recaí diante da aplicação do conhecimento técnico alinhado com o conhecimento relacionado a gestão da empresa rural, para que essa se mantenha sustentável sob um tripé econômico, social e ambiental.

Neste sentido tem-se o desafio de se levar a informação gerencial para o universo rural de forma dinâmica e sobre um formato de fácil assimilação entre os conhecimentos tácitos e científicos necessários para a plenitude do desenvolvimento da administração rural. Para tanto, esta obra intitulada: "Na Ponta do Lápis: Custos da Produção para a Agropecuária" tem por princípio trazer tanto para a academia como para a sociedade rural vários aspectos conceituais de gestão, tanto para as empresas rurais produtoras de royalties, bem como para os produtores da agricultura familiar para que se possa haver a máxima eficiência na redução de custos para que haja maximização de lucros dos negócios agropecuários.

Tem-se então toda uma dinâmica de apresentação dos principais conceitos relacionados as teorias da administração rural, passando a partir desse ponto para uma discussão teórico-prática para que haja uma maior expertise na gestão de custos para a busca da maximização da lucratividade das cadeias produtivas agropecuárias da: Avicultura; Bovinocultura Leiteira; e Suinocultura. Gestão de custos, termo de primeira ordem que move o mundo produtivo das empresas rurais. Tenham uma boa leitura!

Autores:

Aderson Martins Viana Neto

Julyanna Cordeiro Maciel

Laís Dantas Ferreira

Roberta Ramalho Furtado

Samuel Victor de Alcântara Veras 


\section{Sumário}

CUSTOS: INIMIGOS OU ALIADOS?

Introdução

Fatores de produção.

.8

Custos.

O que é a depreciação?

Custo total.

Análise econômica

AVICULTURA.

Introdução

Custos fixos

Custos variáveis.

Itens de custos na avicultura de corte.

Itens de custos na avicultura de postura. 20

BOVINOCULTURA LEITEIRA.

22

Introdução. .23

Custos da bovinocultura. 
Custos variáveis.

Itens de custo da produção em confinamento. 25

Custos da pastagem .26

Custos da ordenha .26

Benchmarking da bovinocultura

\section{SUINOCULTURA}

Introdução 30

Custos na suinocultura. 31

Custos fixos na suinocultura .32

Custos variáveis na suinocultura 32

Custos nas diferentes unidades de produção. 33

Benchmarking da suinocultura 37

TABELA PARA ACOMPANHAMENTO DE OCORRÊNCIAS 39

REFERÊNCIAS BIBLIOGRÁFICAS 40 


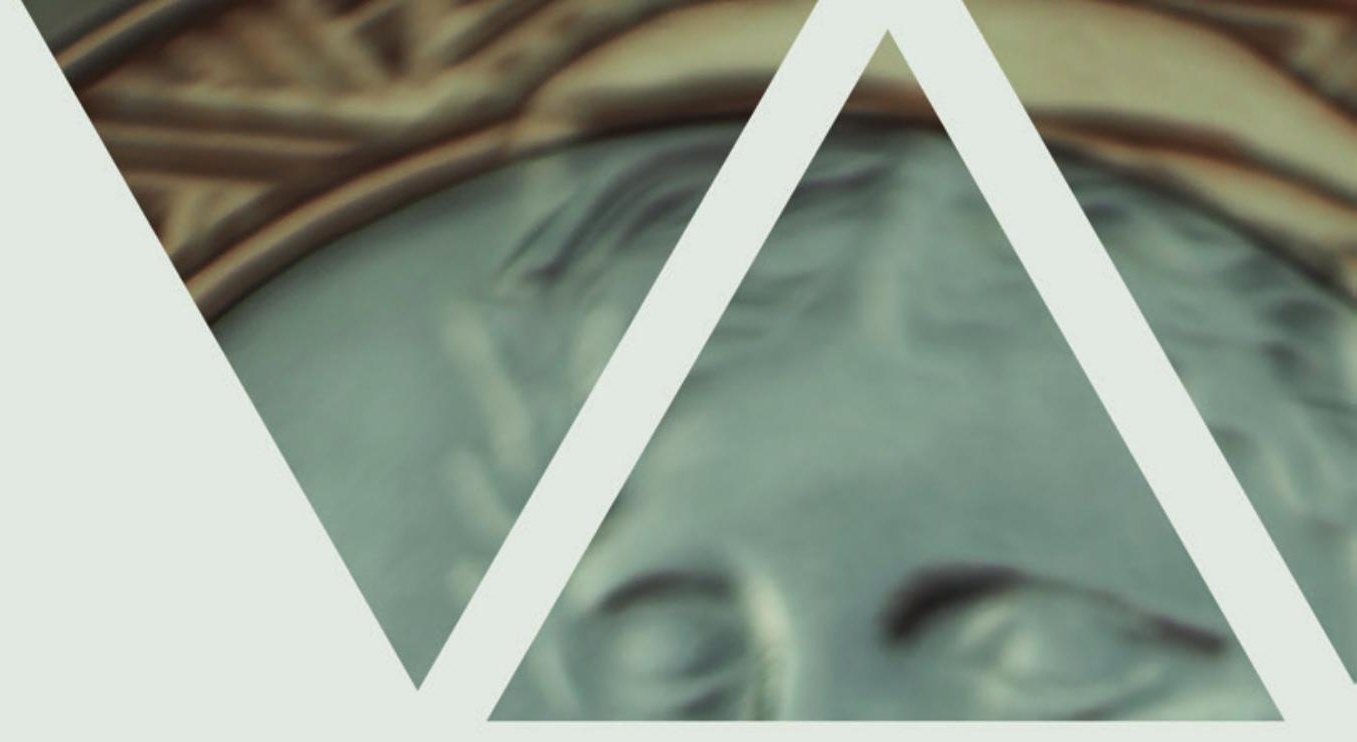

CUSTOS:

INIMIGOS OU ALIADOS? 


\section{Introdução}

O sucesso da empresa rural depende de organização, planejamento, perspectiva do futuro, de fatores internos e externos e controle. Uma boa administração no meio rural leva em consideração a lucratividade do produtor sem depreciar a produtividade da terra (CONAB).

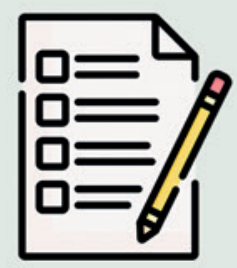

Organização

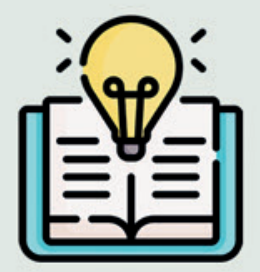

Planejamento

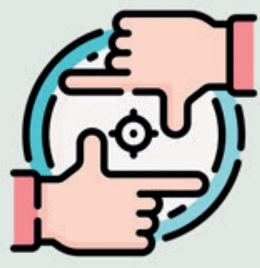

Perspectiva do futuro

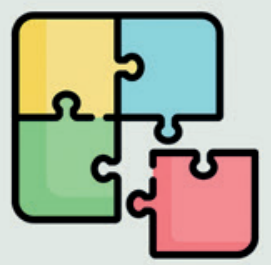

Fatores internos e externos

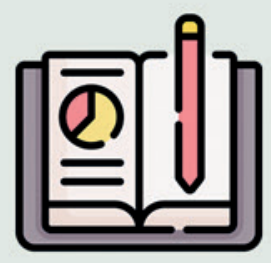

Controle

O conhecimento do custo de produção é importante para a avaliação do negócio, evidenciando lucratividade, continuidade do negócio, melhoria da atividade e da qualidade de vida dos envolvidos.

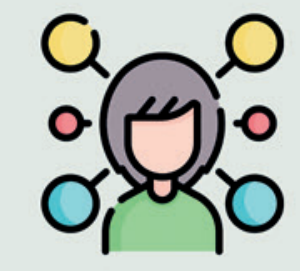

Conhecimento do custo

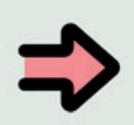

\section{Avaliação do}

Negócio

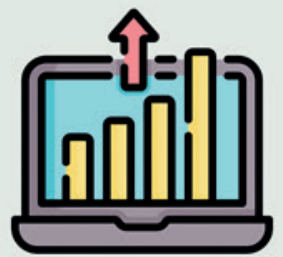

Lucratividade e melhorias

Com uma análise de custos é possivel compreender verdadeiros gastos e organizá-los, levando a uma melhoria administrativa e lucrativa.

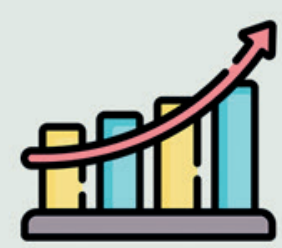




\section{Fatores de produção}

São bens essenciais ao processo de produção, como a terra, o capital e a mão de obra. Esses fatores são finitos, podendo limitar a produção. Sem eles não poderia existir um processo de produção de determinado bem ou serviço.

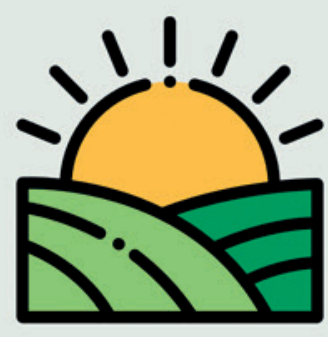

Terra

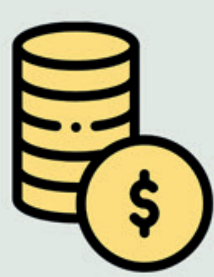

Capital

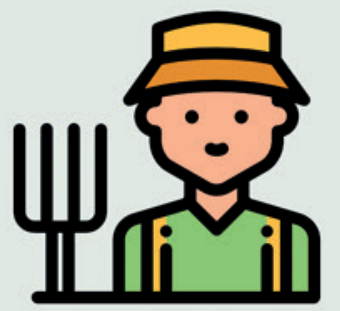

Mão de obra

Esses fatores podem ser fixos (que perduram por mais de um ciclo produtivo) ou variáveis (que são consumidos durante o processo produtivo).

\section{Custos}

São os gastos envolvidos com a produção. Representam tudo o que foi aplicado para obter um determinado produto, ou seja, quanto foi gasto para se produzir aquilo que a propriedade rural tem como produto, seja este um litro de leite, uma arroba de boi, uma dúzia de ovos, uma leitegada. Alguns exemplos são:

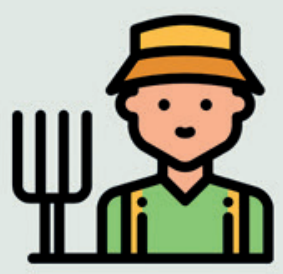

Mão de obra

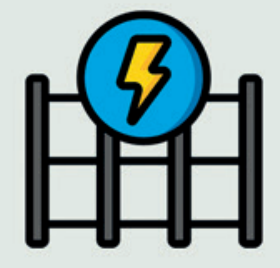

Energia elétrica

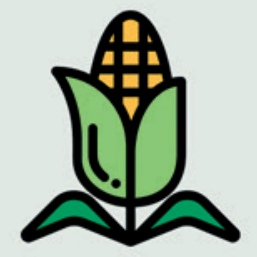

Milho e soja

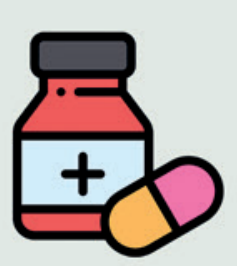

Medicamentos

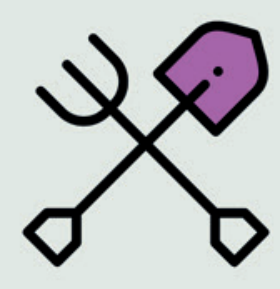

Materiais de limpeza

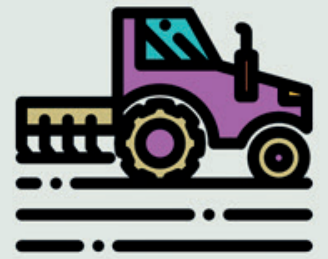

Manutenção de equipamentos

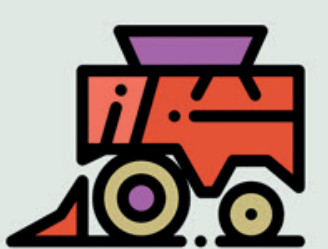

Depreciação de equipamentos 
Os custos diretos podem ser associados diretamente ao produto, bem ou linha de produção, tendo um valor aplicável. São exemplos:

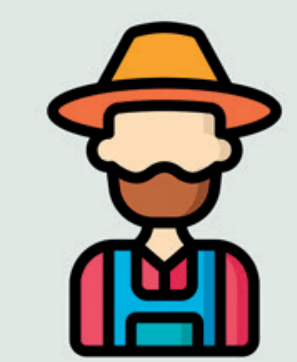

Mão-de-obra direta

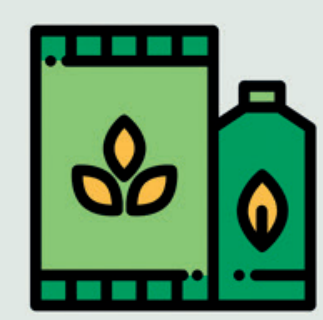

Matéria-prima

Já nos custos indiretos, não é possivel atribuir o valor exato deles em uma unidade produzida. São exemplos:

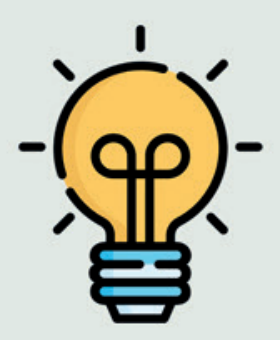

Energia

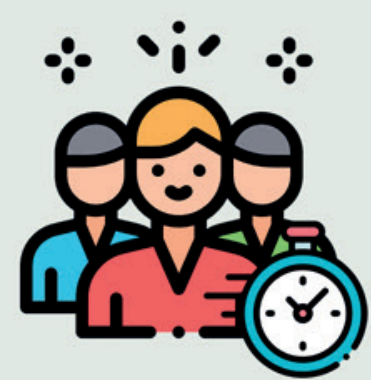

Mão-de-obra administrativa

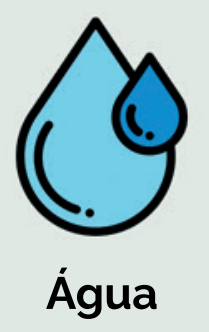

Água

\section{Os custos podem ainda ser classificados em VARIÁVEIS ou FIXOS!}

Os custos variáveis correspondem aos custos dos itens consumidos durante o processo produtivo, ou ainda, que precisam estar sendo repostos de tempos em tempos. Estes variam de acordo com o nivel de produção. São exemplos:

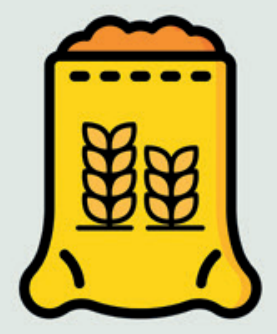

Alimentação dos animais

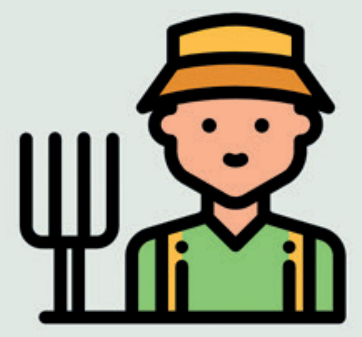

Mão-de-obra

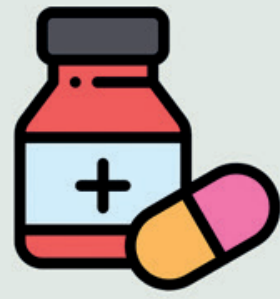

Produtos veterinários 
Os custos fixos são aqueles que não variam, se mantendo os mesmos em todos os meses, independente da quantidade produzida. São exemplos:

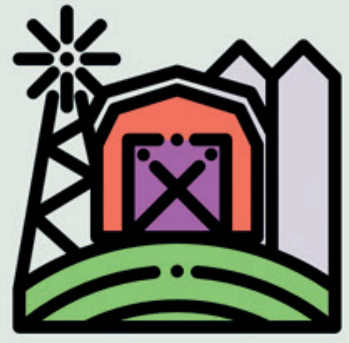

Depreciação de instalações

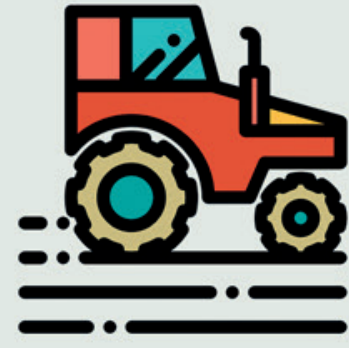

Depreciação de máquinas

\section{O que é a depreciação?}

A depreciação consiste na perda do valor de um determinado bem. Ela pode levar em conta inúmeros fatores, como o desgaste natural, o tempo de vida útil e até mesmo a quantidade de vezes que esse bem foi utilizado. Mas como calcular a depreciação de um bem?

CÁlCULO DA DEPRECIAÇÃo PELO MÉTODO LINEAR

Depreciação $=\left(\frac{\text { Valor inicial }- \text { Valor final }}{\text { Vida útil }}\right)$

O método linear consiste na forma mais simples de se obter a depreciação. Nela, se divide o valor do equipamento (inicial e final) pelo seu tempo de vida útil.

\section{LEGENDAS}

Valor inicial = Quantia paga quando o material foi adquirido;

Valor final = Preço que ele custaria no final da sua vida útil;

Vida útil = Tempo em que esse bem pode ser usado para realizar um função; 


\section{Custo total}

O custo total consiste na soma dos custos fixos com os custos variáveis, estabelecendo o valor total que foi utilizado em todo um mês ou período escolhido.

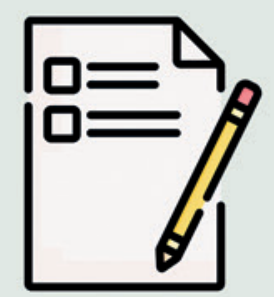

Custos fixos

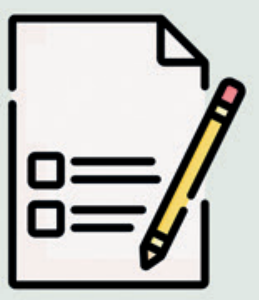

Custos variáveis

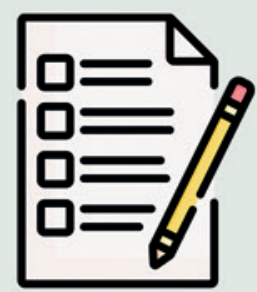

Custos totais

\section{Análise econômica}

Compreende um conjunto de técnicas que visam demonstrar a situação financeira da sua produção. Alguns exemplos são:

\section{OBTENÇÃO DE RENDA BRUTA}

\section{Renda Bruta $(\mathrm{RB})=$ Quant. vendida $\times$ Preço do litro}

Na obtenção da renda bruta é calculado o valor total recebido pela venda do produto.

Exemplo: Venda de $\underline{300 ~ L ~ d e ~ l e i t e, ~ s a i n d o ~ p o r ~} \underline{\mathrm{R} \$ 1,25 \text { cada litro, }}$ durante um mês

Renda Bruta (RB) $=300 \times 1,25 \times 30$

Renda Bruta $(R B)=11.250$ reais 


\section{OBTENÇÃO DE CUSTOS FIXOS}

Custos Fixos (CF) $=$ Custo Fixo $01+$ Custo Fixo $02+\ldots \ldots .+$ Custo Fixo $\mathrm{N}$

A obtenção de custos fixos consiste na soma de todo valor aplicado na categoria de custos fixos.

Exemplo: Uma produção com Depreciação de Instalações de R $\$ 1.900,00 \mathrm{e}$

Depreciação de Equipamentos de R $\$ 3.500,00$

Custos Fixos (CF) $=1.900+3.500$

Custos Fixos (CF) $=\mathbf{5 . 4 0 0}$

\section{OBTENÇÃO DE CUSTOS VARIÁVEIS}

Custos Var. (CV) = Custo Var. $01+$ Custo Var. $02+$ + Custo Var N

A obtenção de custos variáveis consiste na soma de todo valor aplicado na categoria de custos variáveis.

Exemplo: Uma produção com Custo de Mão-de-obra de R\$2.000,00, Custo de Ração de $\mathbf{R} \$ 500,00$ e Custo de Água de $\mathbf{R} \$ 100,00$

Custos Variáveis $(\mathrm{CV})=2.000+500+100$

Custos Variáveis $(\mathrm{CV})=\mathbf{2 . 6 0 0}$ 
Pode-se calcular a margem bruta, ou seja, se a receita é superior pelo menos aos custos variáveis.

\section{OBTENÇÃO DE MARGEM BRUTA}

Margem Bruta (MB) = Renda Bruta (RB) - Custos Variáveis (CV)

Margem Bruta $(M B)=11250-2600$

Margem Bruta $(M B)=8650$

Com a obtenção da Margem Bruta você sabe quanto entrou de dinheiro com a venda do seu produto. Após o somatório dos Custos Fixos com os Custos Variáveis você obtém o custo total, ou seja, o quanto foi gasto para produzir. Com esse resultado (CF + $\mathrm{CV}$ ), subtraído da MB, conseguimos obter o resultado (lucro ou prejuizo).

\section{OBTENÇÃO DE MARGEM LIQUIDA}

Margem Líquida $(M L)=$ Margem Bruta - (Custos Fixos + Custos Variáveis)

Margem Líquida (ML) $=11250-(5400-2600)$

Margem Líquida $(\mathrm{ML})=3250$ 
$\leftrightarrow$

Dि जि

[O 


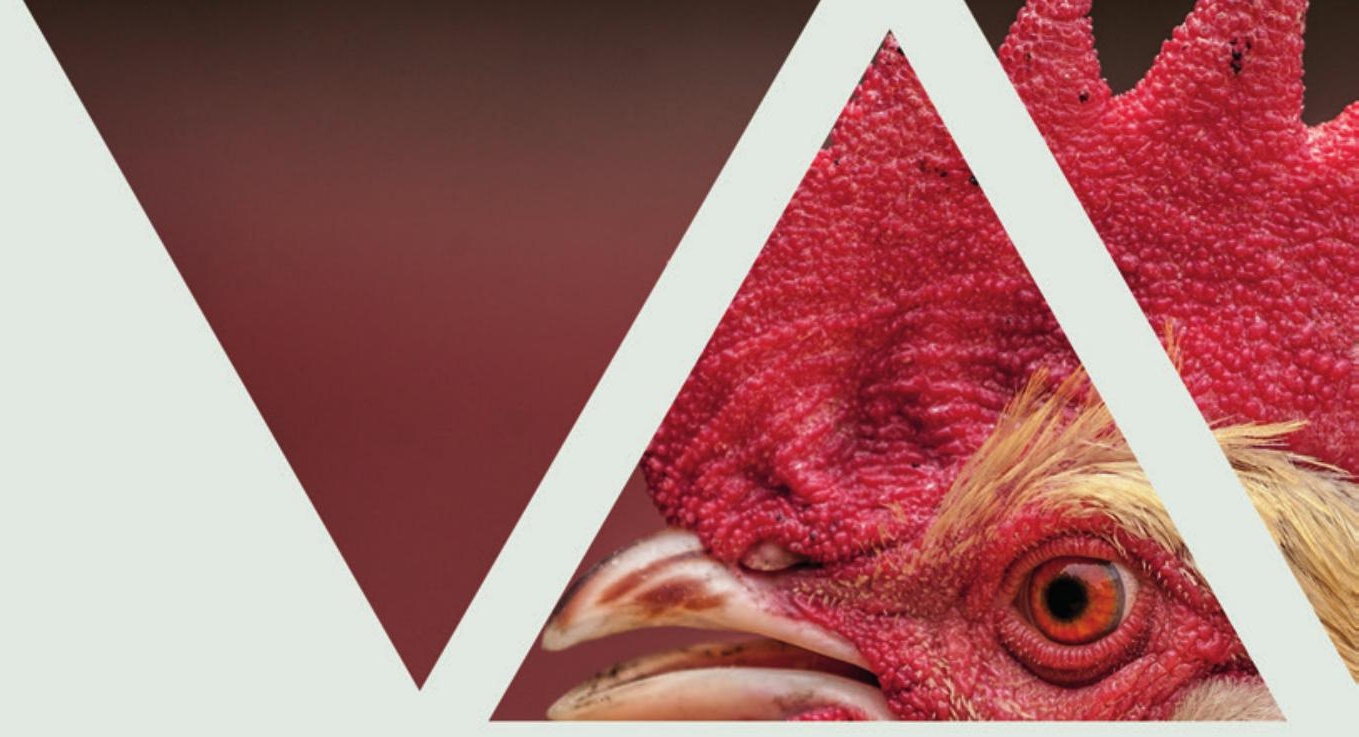

\section{AVICULTURA}
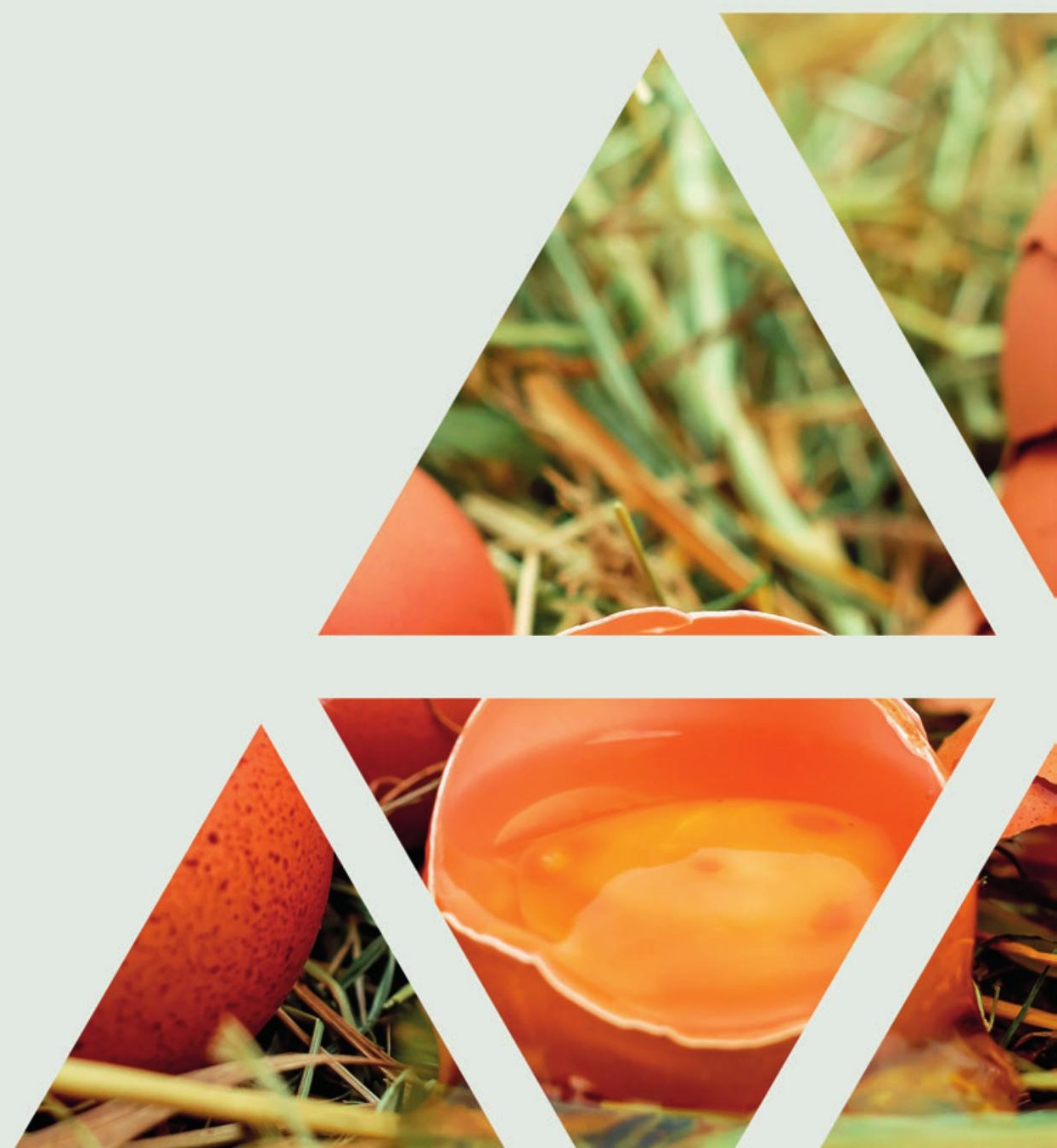


\section{Introdução}

Na América Latina, o Brasil é o segundo maior produtor e exportador de carne de frango, sendo o estado do Paraná o maior produtor nacional de frango de corte.

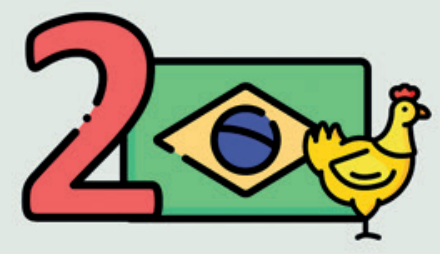

\section{Os custos na avicultura podem variar de acordo com as etapas do processo produtivo.}

Como exemplos dos diversos custos nas variadas etapas de produção da avicultura, podemos citar:

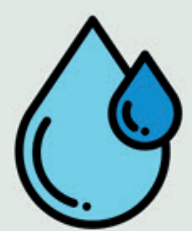

Água

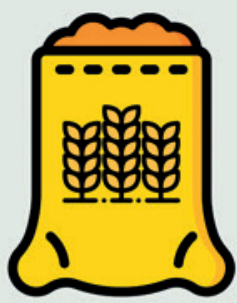

Ração

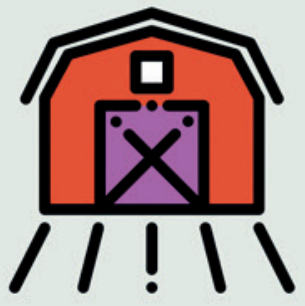

Manutenção de instalações

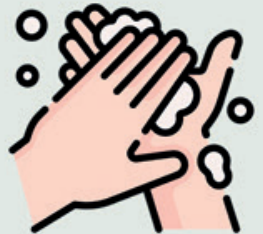

Material de limpeza

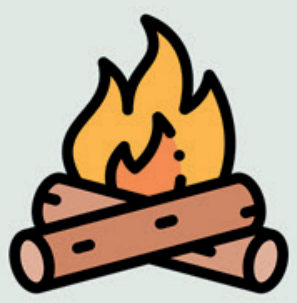

Aquecimento

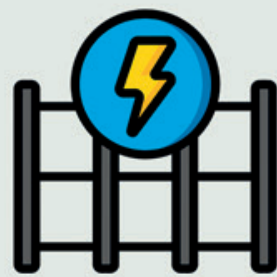

Energia elétrica

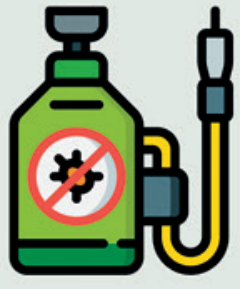

Produtos químicos

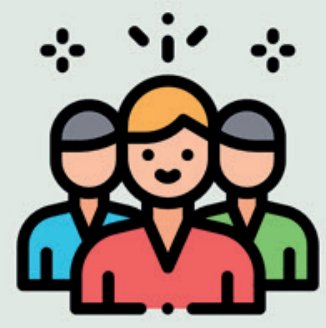

Mão-de-obra

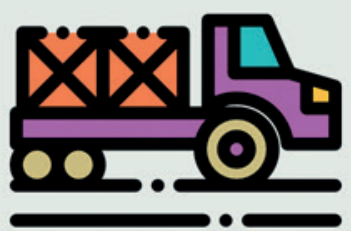

Transporte 
Dentre as etapas que abrangem essa gama de custos, podemos citar:

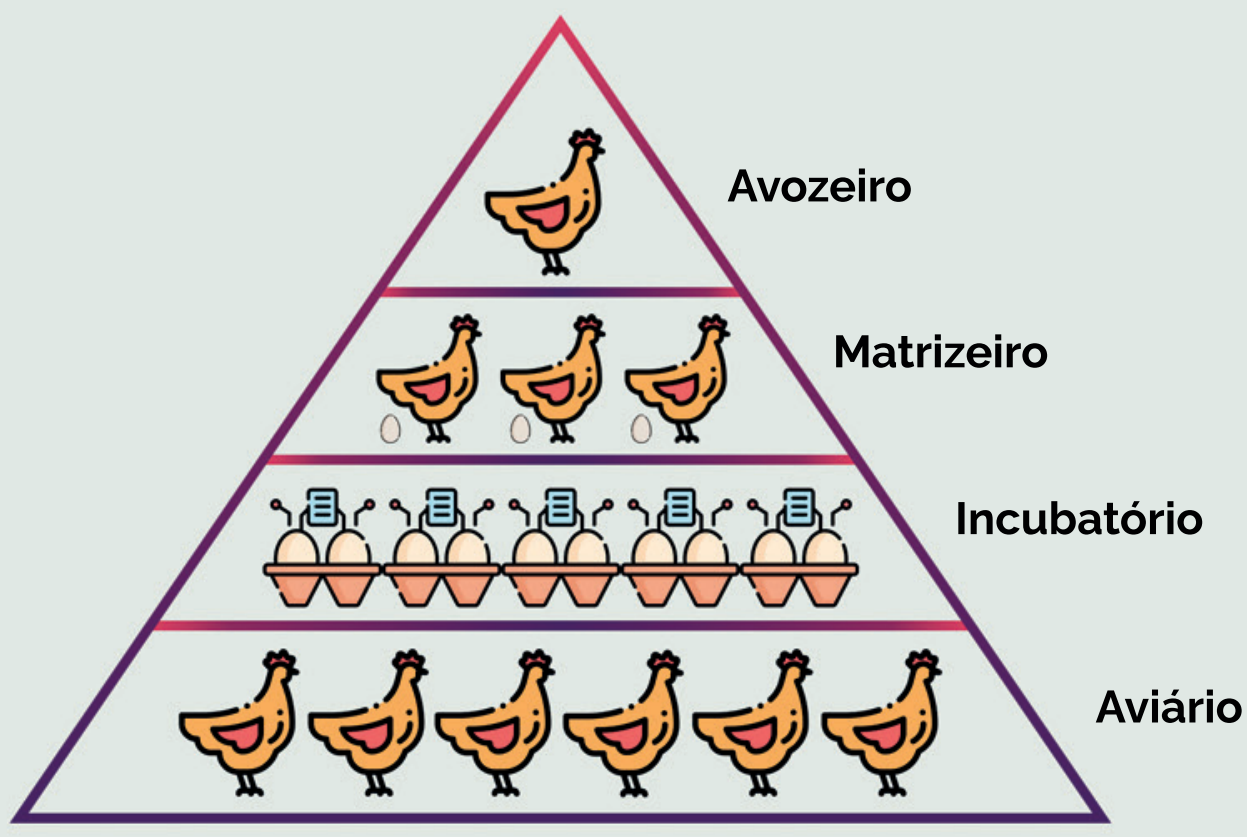

Para melhor análise e controle financeiro, os custos nessas etapas de produção podem ser divididos em: custos fixos e custos variáveis.

\section{Custos fixos}

Os custos fixos são aqueles que, independentemente da quantidade produzida, se mantém constantes, sem variar com o volume da produção. Assim, podemos classificar como exemplos de custos fixos na avicultura:

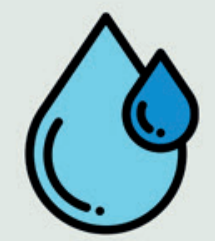

Água

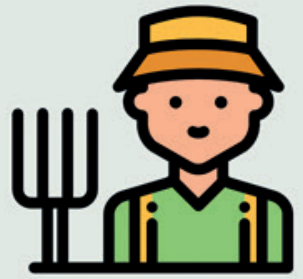

Mão-de-obra fixa

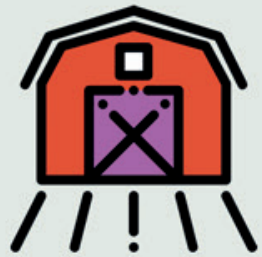

Depreciação de instalações

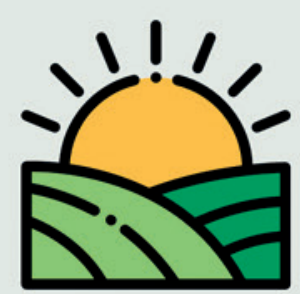

Imposto territorial rural

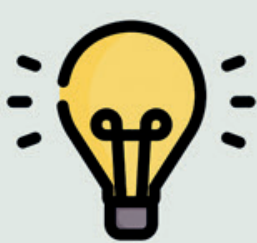

Energia elétrica 


\section{Custos variáveis}

Os custos variáveis são aqueles que aumentam de acordo com o aumento da produção, sendo "consumidos" durante o processo produtivo. Assim, podemos classificar como exemplos de custos variáveis na avicultura:

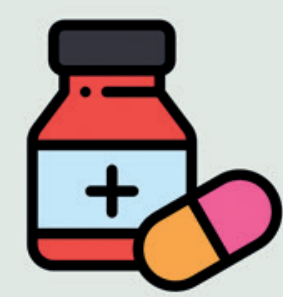

Medicamentos

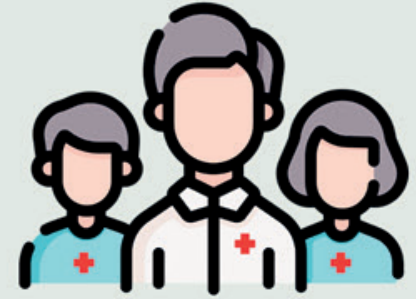

Consulta veterinária

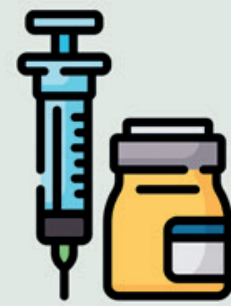

Vacinas

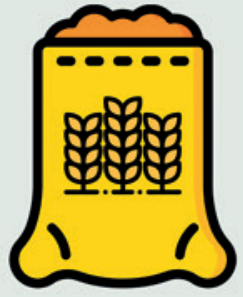

Ração

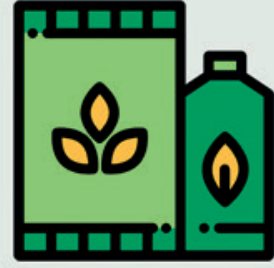

Núcleo

vitamímico-mineral

\section{Itens de custos na avicultura de corte}

A avicultura de corte consiste na produção de aves que serão criados e destinadas ao abate.

\section{Como itens de custos fixos da avicultura de corte temos:}

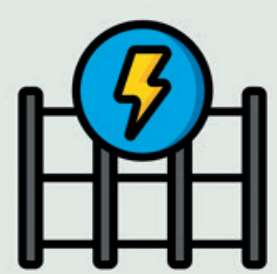

Manutenção elétrica

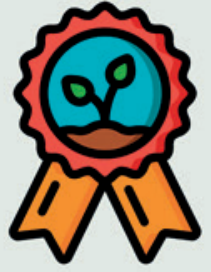

Licença ambiental

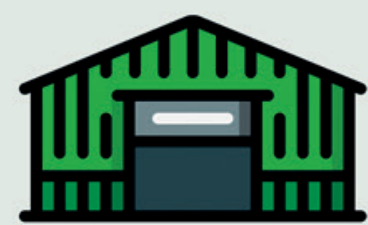

Depreciação de instalações

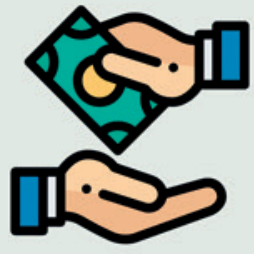

Aluguel

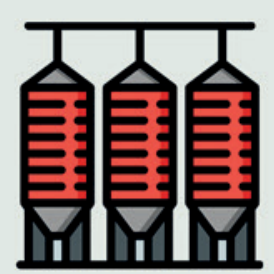

Depreciação de equipamentos 


\section{Como itens de custos variáveis da avicultura de corte temos:}

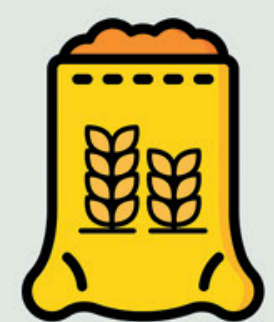

Ração

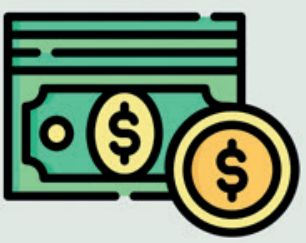

Despesas administrativas

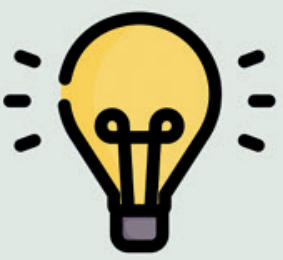

Energia elétrica

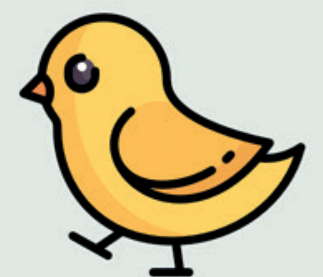

Pintos de um dia

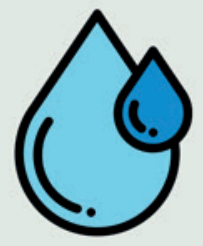

Água

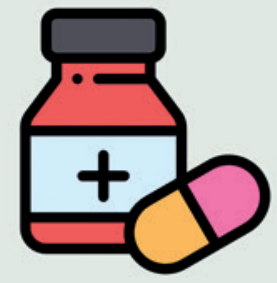

Produtos veterinários

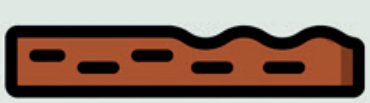

Cama

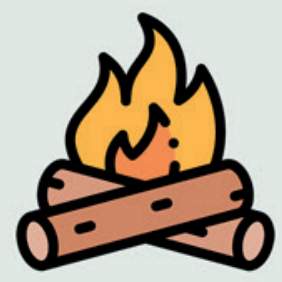

Calefação

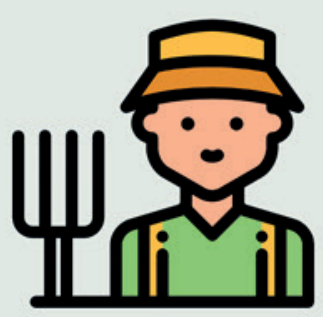

Mão-de-obra

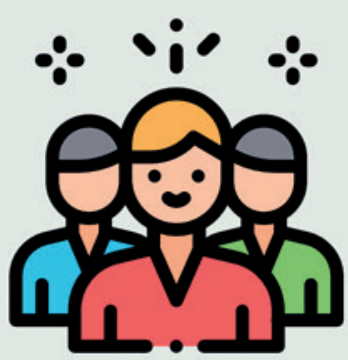

Assistência técnica 


\section{Itens de custos na avicultura de postura}

Avicultura de postura consiste na criação de galinhas para produção de ovos, conhecidas popularmente por poedeiras. Podemos dividi-la em postura para consumo e postura para reprodução.

\section{Como itens de custos fixos da avicultura de postura temos:}

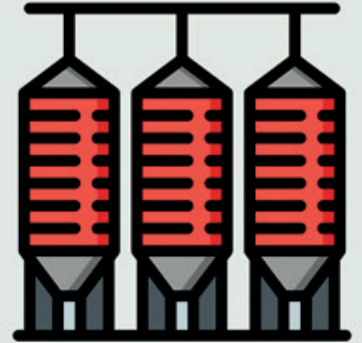

Depreciação de equipamentos

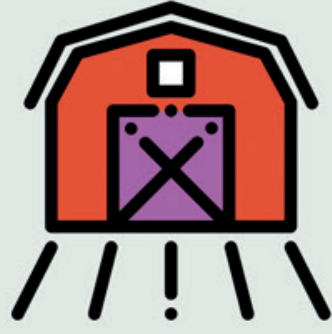

Depreciação de instalações

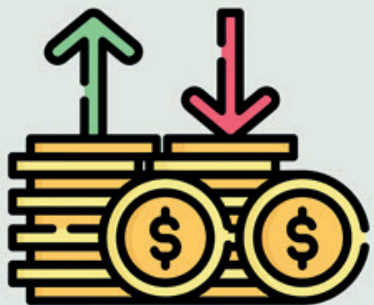

Juros sobre capital de giro

\section{Como itens de custos fixos da avicultura de postura temos:}

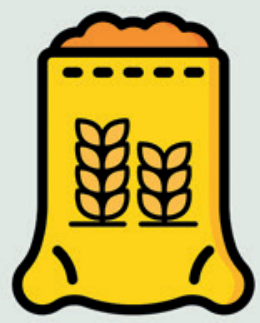

Ração

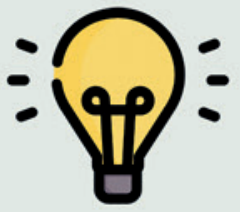

Energia elétrica

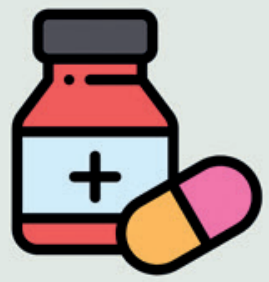

Produtos veterinários

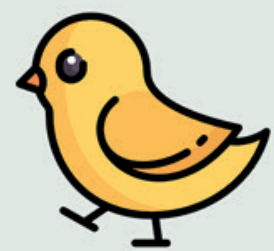

Pintainhas

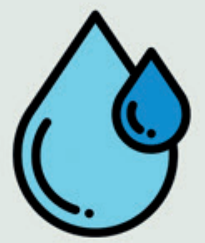

Água

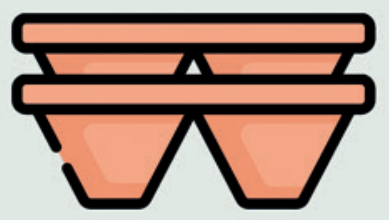

Embalagens

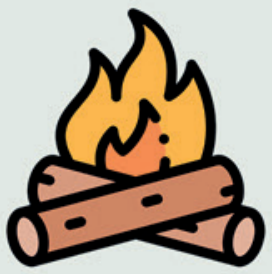

Calefação

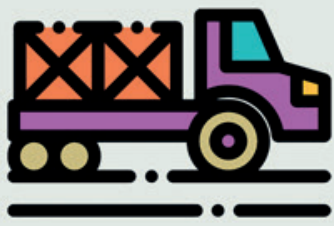

Transporte

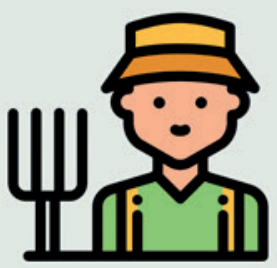

Mão-de-obra 
$\leftrightarrow$

Dि जि

[O 

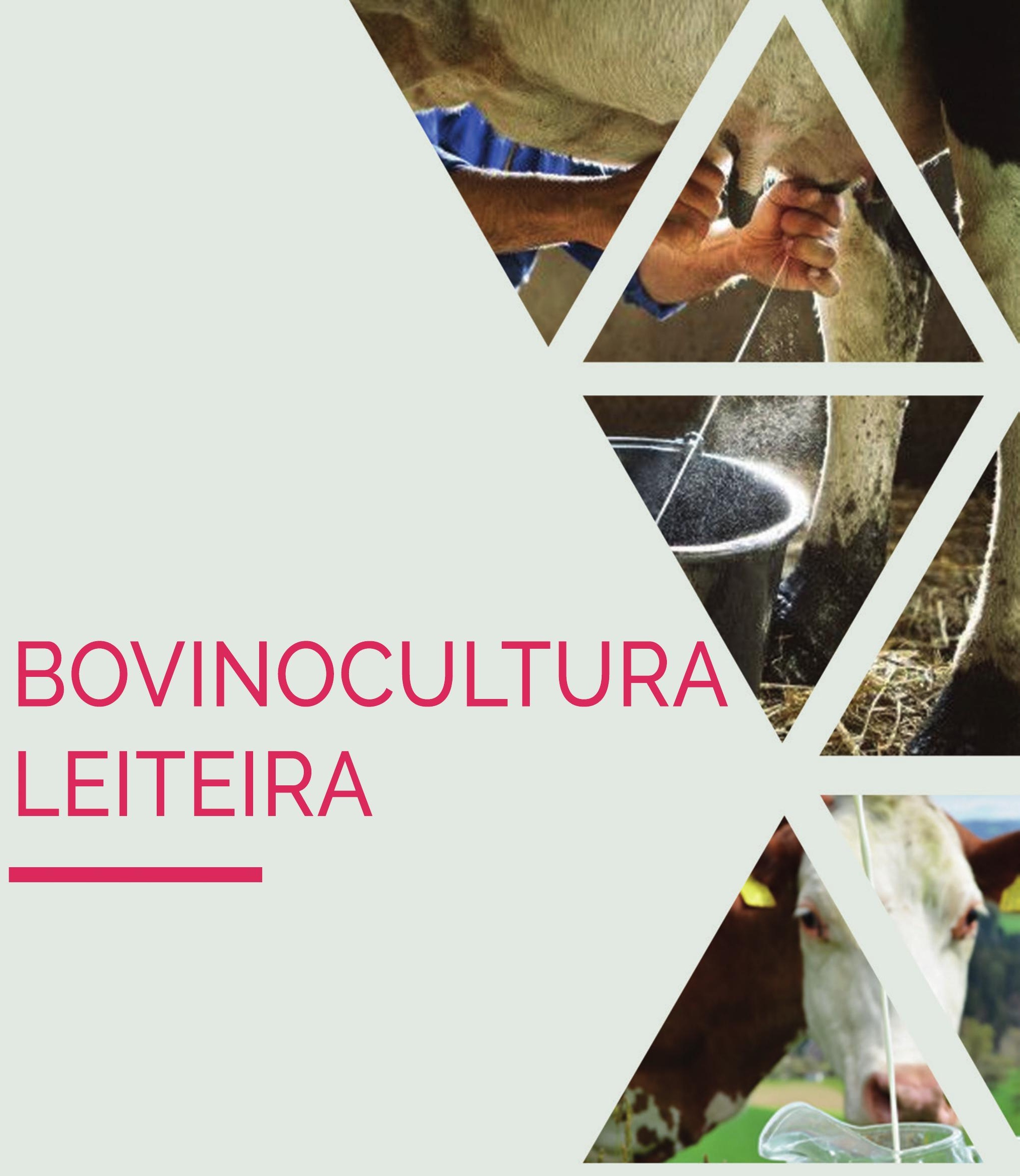


\section{Introdução}

A produção de leite bovino em todo o mundo segue em crescimento, aumentando 44\% nos anos de 2000 a 2015 entre os maiores produtores, incluindo o Brasil.

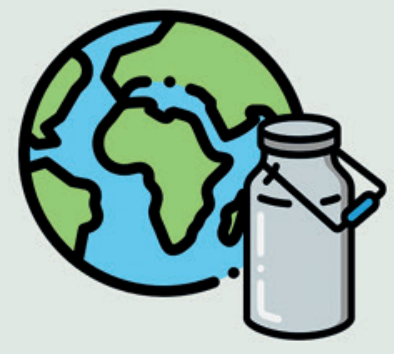

\section{Produção mundial de leite em 2015: $656.000 \mathrm{~L}$}

O Brasil ocupa o quarto lugar na produção mundial de leite, sendo responsável pela produção de $7 \%$ do leite produzido no mundo.

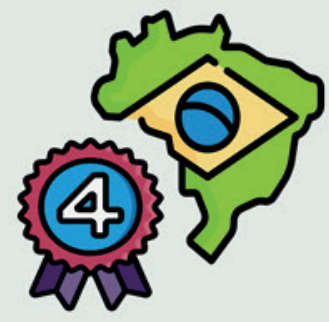

Um produtor da bovinocultura precisa ficar atento a inúmeros fatores, que possam levar a prejuizos ou maximização de sua produção. Atentando-se a esses pontos, é possivel amortecer custos não programados.
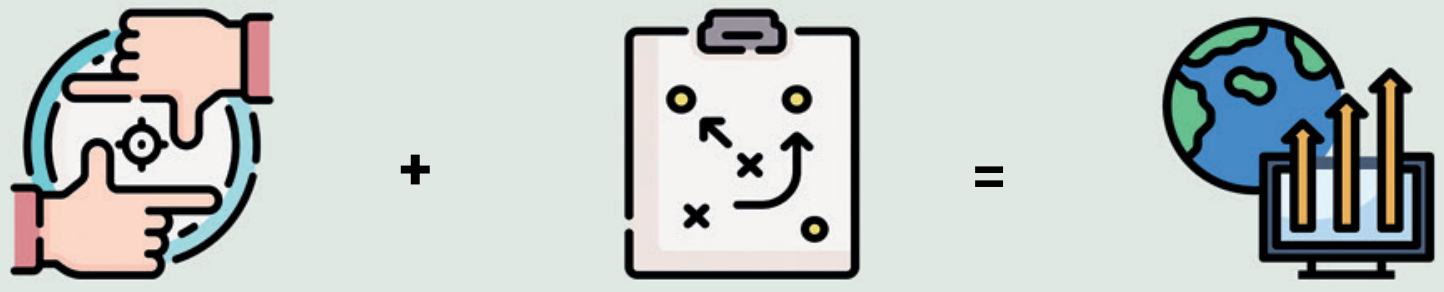

\section{Custos na bovinocultura}

A bovinocultura apresenta diferentes custos, como aqueles relacionados a compra de ração, de animais, de medicamentos, salários/diárias de funcionários, além daqueles associados à manutenção de equipamentos, compra de combustivel, entre outros.

Alguns exemplo de custos na bovinocultura leiteira são: 


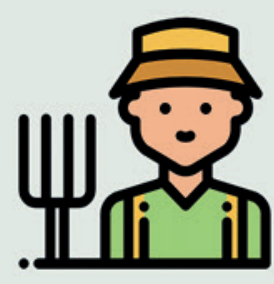

Mão-de-obra

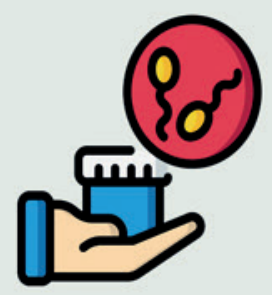

Sêmen

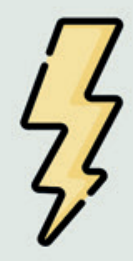

Energia

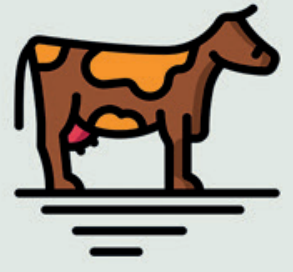

Compra de animais

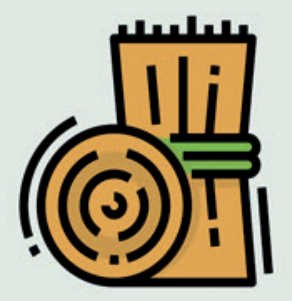

Ração

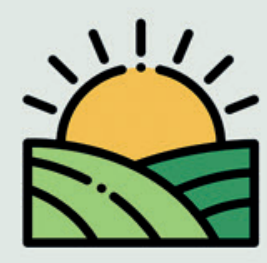

Pastagem
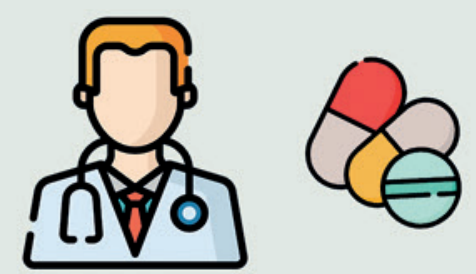

Assistência veterinária

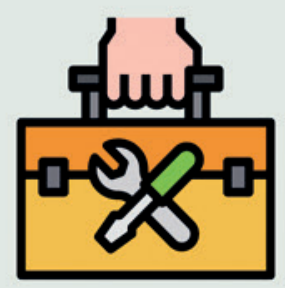

Manutenção de equipamentos e instalações

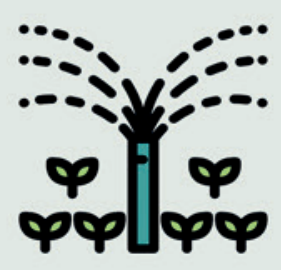

Água

Custos fixos

Os custos fixos são aqueles que independente da quantidade produzida se mantém constante, independente da quantidade produzida. Alguns exemplos de custos fixos:

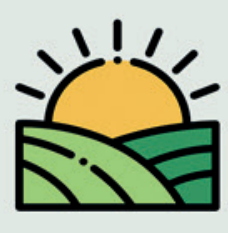

Pastagem

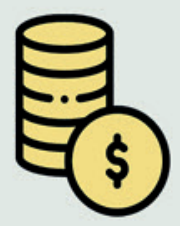

Encargos sociais e trabalhistas

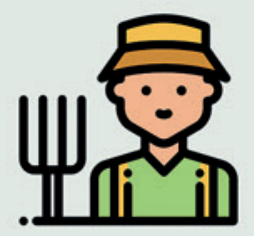

Mão-de-obra

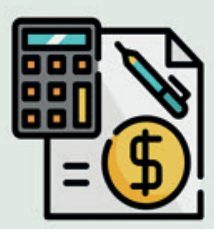

Impostos e taxas

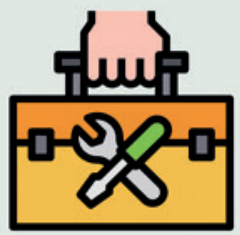

Depreciação de equipamentos e instalações

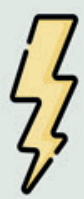

Energia

24 


\section{Custos variáveis}

Os custos variáveis são aqueles que variam de acordo com qa quantidade produzida, sendo consumidos durante o processo de produção, precisando ser repostos. Alguns exemplos de custos variáveis:

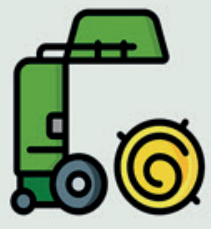

Volumoso

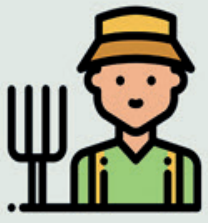

Mão-de-obra eventual

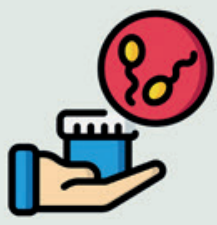

Sêmen

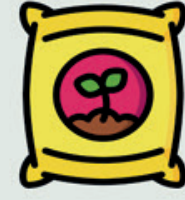

Adubo

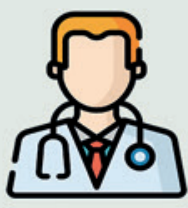

Medicamentos, vacinas e médico veterinário

\section{Itens de custo da produção em confinamento}

A eficiência e rentabilidade, nesse modelo de produção, só é possivel quando bem executado o processo de implantação e manutenção das instalações, como galpões, eletricidade, equipamentos que podem conter um elevado custo. Podemos citar como itens de custos da produção em confinamento:

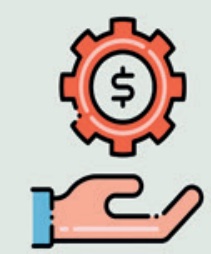

Manutenção das instalações

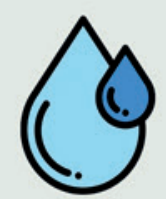

Água

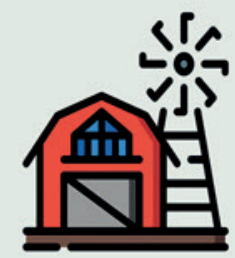

Implantação das instalações

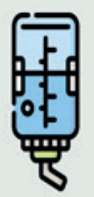

Bebedouros

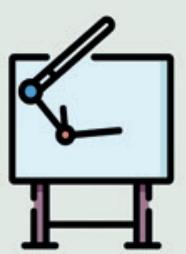

Projeto arquitetônico

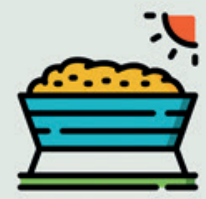

Comedouros

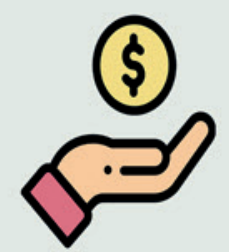

\section{Remuneração} familiar

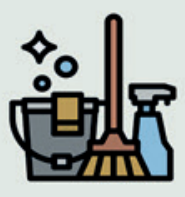

Limpeza 


\section{Custos da pastagem}

A qualidade do pasto deve proporcionar aos animais o máximo de nutrientes possivel. Podemos considerar itens de custos referentes à implantação e/ou manutenção da pastagem:

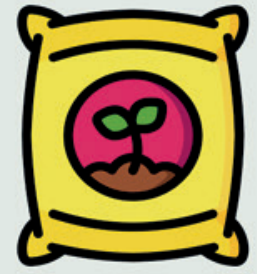

Adubo

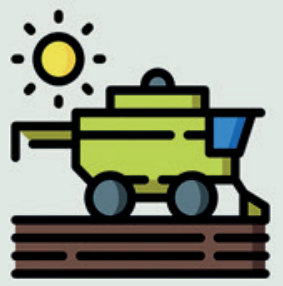

Preparo do solo

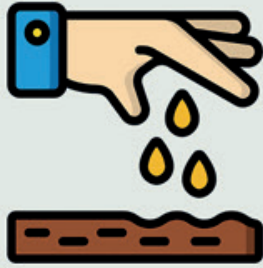

Sementes de qualidade

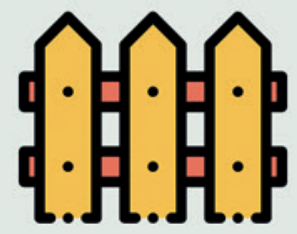

Cercas

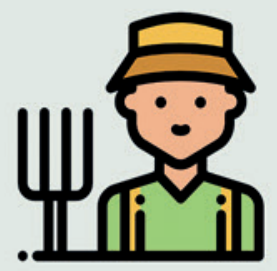

Mão-de-obra

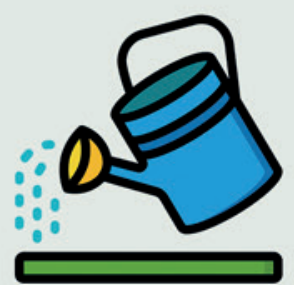

Irrigação

\section{Custos da ordenha}

A etapa essencial da atividade leiteira é a ordenha, que consiste na retirada do leite seja por modo manual ou mecânico. A rotina de ordenha inclui itens custos relacionados à:

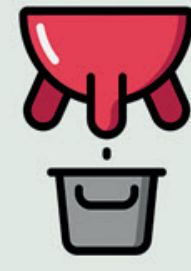

Baldes

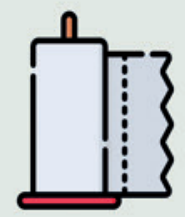

Papel toalha

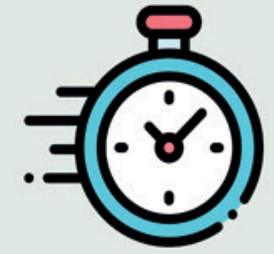

Horas trabalhadas

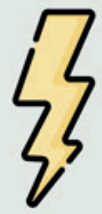

Energia elétrica

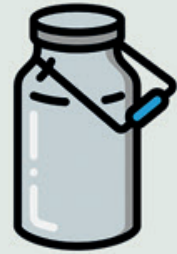

Galão de leite

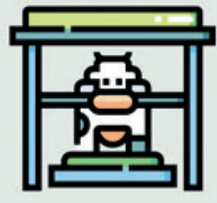

Manutenção do Curral de ordenha 


\section{Benchmarking da bovinocultura}

Benchmarking pode ser definido como:

A mensuração do desempenho através da comparação de indicadores técnicos com aqueles obtidos por outros agentes do mesmo setor, ou seja, comparar os seus índices com aqueles obtidos por outras fazendas.

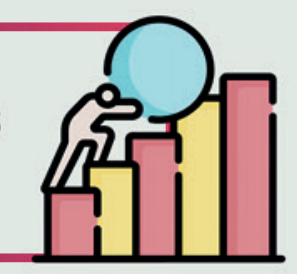

O Índice Ideagri do Leite Brasileiro (IILB) oferece informações de indicadores produtivos e reprodutivos de produções de bovinos leiteiros com diferentes perfis e regiões. Assim, os dados apresentados abaixo foram obtidos do IILB-8, referente à avaliação entre outubro de 2019 a setembro de 2020, destacando uma tendência à melhoria do índice.

\section{BENCHMARKING - BOVINOCULTURA LEITEIRA}

\begin{tabular}{|c|c|c|c|}
\hline \multirow{2}{*}{ Parâmetro } & \multirow{2}{*}{$\begin{array}{l}\text { ÍNDICE IDEAGRI* } \\
\text { IILB8 - Brasil } 2020\end{array}$} & \multicolumn{2}{|c|}{ PESSOAL** $^{* *}$} \\
\hline & & Ano & Ano \\
\hline \% de vacas em lactação em relação ao total de vacas & $81,2 \%$ & & \\
\hline Taxa de prenhez em vacas (\%) & $19,7 \%$ & & \\
\hline Produção média mensal vaca (Kg) & $24,8 \mathrm{~kg}$ & & \\
\hline Primiparas - Produção de leite - 305 dias (Kg) & $6.401 \mathrm{~kg}$ & & \\
\hline Multiparas - Produção de leite - 305 dias (Kg) & $7.170 \mathrm{~kg}$ & & \\
\hline Dias em lactação médio & 178 dias & & \\
\hline Taxa de mortalidade de vacas (\%) & $6,7 \%$ & & \\
\hline Taxa de sobrevivência fêmeas 12 meses (\%) & $85.3 \%$ & & \\
\hline Idade das novilhas ao primeiro serviço (meses) & 18,2 meses & & \\
\hline Taxa de concepção novilhas (\%) & $47,8 \%$ & & \\
\hline Idade ao primeiro parto das matrizes (meses) & 29,6 meses & & \\
\hline Perda de prenhez de vacas (\%) & $18,3 \%$ & & \\
\hline Perda de prenhez de novilhas (\%) & $9,4 \%$ & & \\
\hline
\end{tabular}

•Índice ideagri do leite Brasileiro (IILB8), obtidos entre outubro de 2019 e setembro de 2020. Disponivel no site: web.ideagri.com.br/ideagriweb/iilb/process/lilbBiblioteca

". Para uso pessoal, a fim de que o produtor anote seus indices e compare-os com aqueles apresentados. 
$\leftrightarrow$

Dि जि

[O 

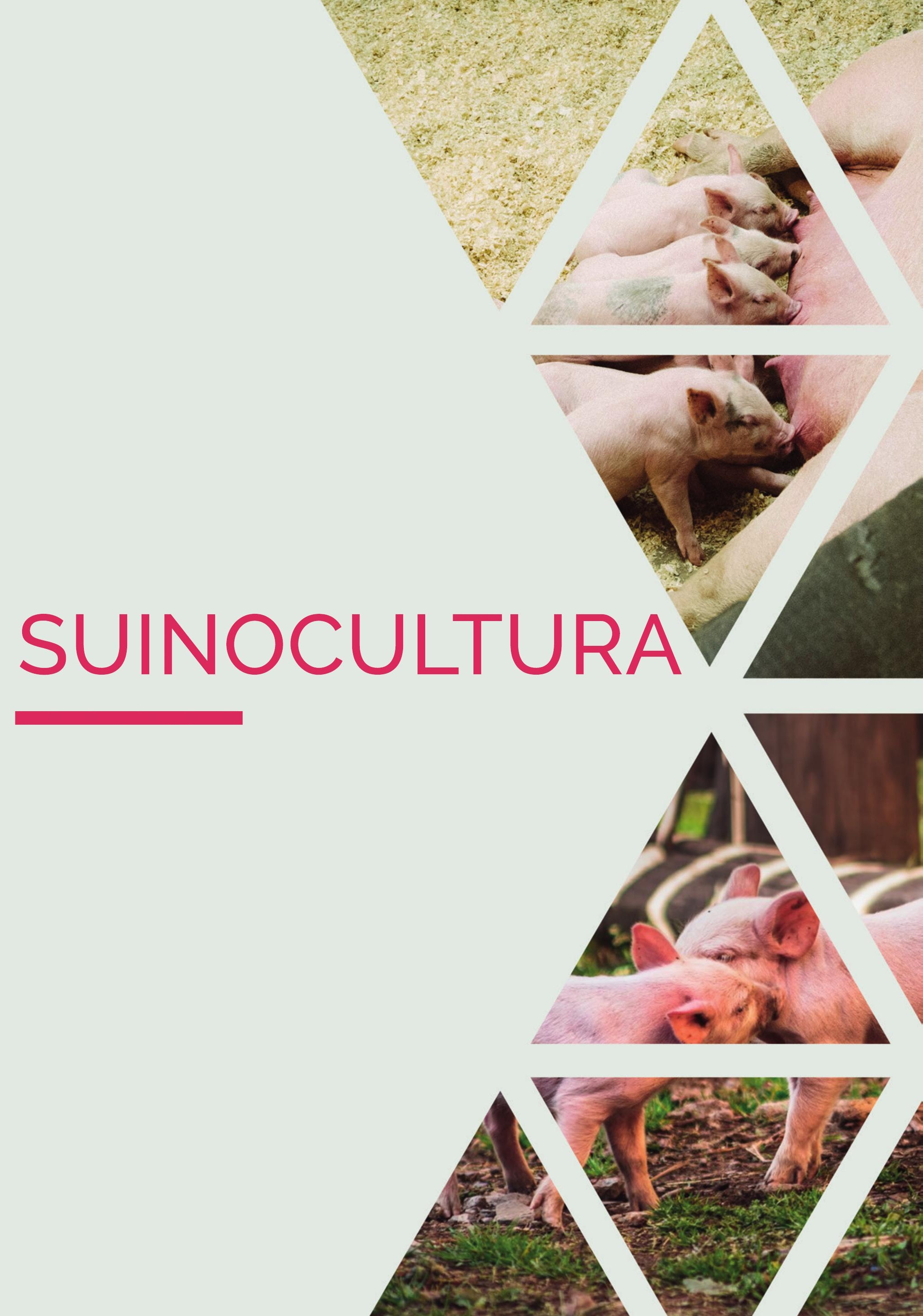


\section{Introdução}

A carne suína é considerada a mais produzida no mundo, demonstrando a grandeza desse mercado. O Brasil exporta para cerxa de 70 paises, sendo $04^{\circ}$ maior produtor de suinos no mundo, com potencial de expandir essa produção.

\section{Em 2015 \\ Rebanho de suínos em reprodução no Brasil: \\ 1.720 .255 matrizes. \\ Suínos produzidos para abate: \\ 39 milhões \\ PIB da suinocultura no Brasil : \\ $\mathrm{R} \$ 62,576$ bilhões.}

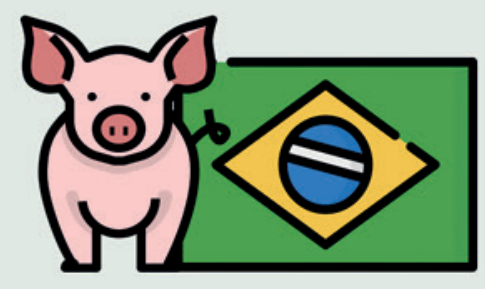

É de grande importância compreender os custos na suinocultura, uma vez que refletem a eficiência com que a atividade está sendo desenvolvida, auxiliando ainda na tomada de decisão. Além disso, auxilia na redução do risco de prejuízos no final de todo o ciclo de produção e venda, propiciando ainda que o produtor esteja atento ao mercado, sendo esse um fator influenciador direto na sua produção.

Dessa forma, esta cartilha evidencia os custos na suinocultura, fixos e variáveis, além de destacá-los conforme o modelo de produção:

\section{Unidade Produtora de Leitões (UPL)}

\section{Unidade de Terminação (UT)}

Unidades de Ciclo Completo (UCT) 


\section{Custos na suinocultura}

Ainda que a suinocultura se organize em três principais fases ou ainda em unidades de produção, grande parte dos itens de custos são semelhantes entre si.

FASES

Maternidade

Creche

Terminação

\section{MODELOS}

Unidade Produtora de Leitões (UPL)

Unidade de Terminação (UT)

Unidades de Ciclo Completo (UCT)

Desta forma, temos como exemplos de fontes de custos na suinocultura:

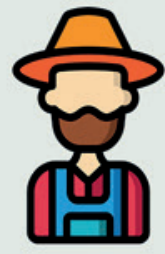

Mão-de-obra

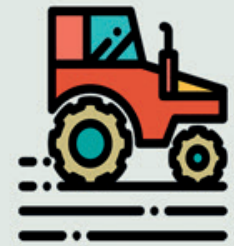

Depreciação de máquinas

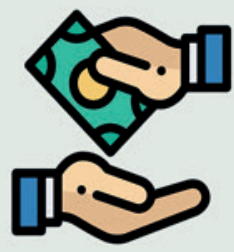

Encargos sociais e trabalhistas

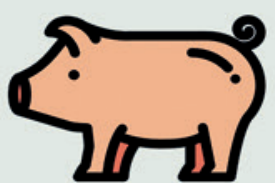

Compra de animais

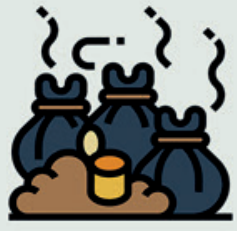

Armazenagem e distribuição de dejetos

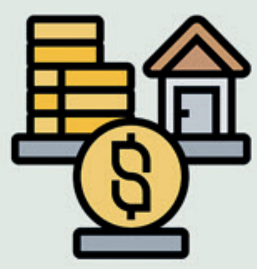

Aluguéis

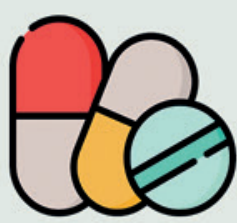

Medicamentos

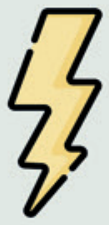

Energia e aquecimento

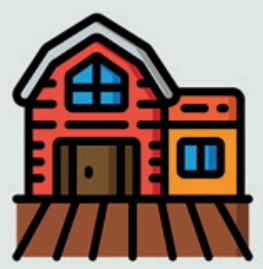

Seguro de prédios e instalações

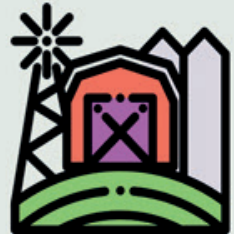

Depreciação de instalações

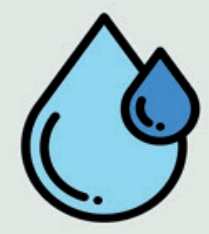

\section{Consumo de} água

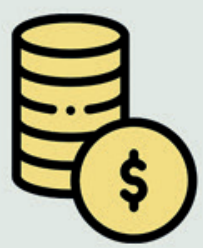

Despesas administrativas 


\section{Custos fixos na suinocultura}

A curto prazo temos como custos fixos, aqueles que independente da quantidade produzida se mantém constantes, e os custos variáveis dependem do volume produzido. Sao exemplos de custos fixos:

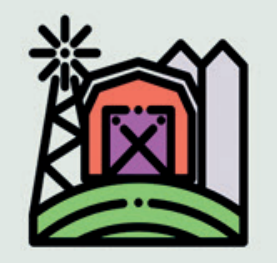

Depreciação de instalações

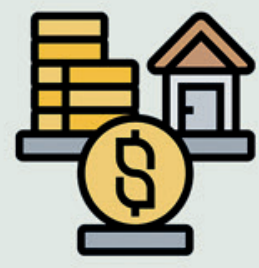

Aluguéis

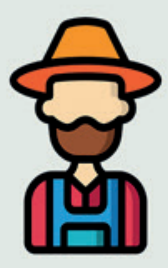

Mão-de-obra

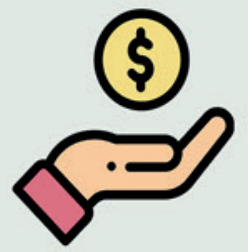

Impostos e taxas

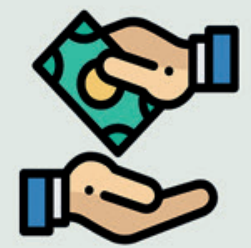

Encargos sociais e trabalhistas

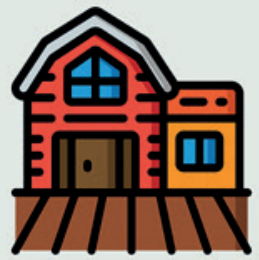

Seguro de prédios e instalações

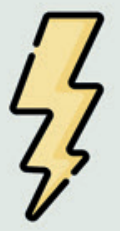

Energia e aquecimento

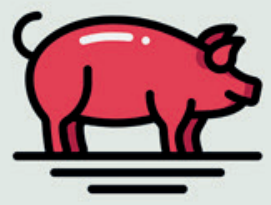

Reposição de reprodutores

\section{Custos variáveis na suinocultura}

Consideramos como custos variáveis aqueles que são consumidos durante o processo produtivo, ou aqueles que precisam ser repostos. São exemplos de custos variáveis:

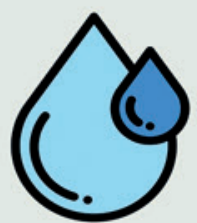

Consumo de água

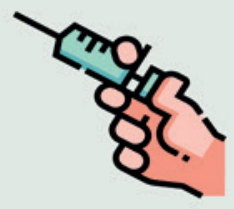

Vacinas

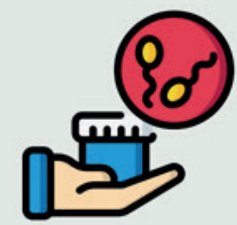

Sêmen para reprodução

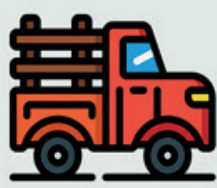

Transporte

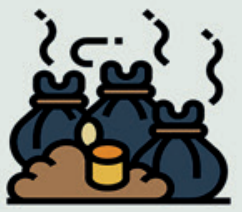

Armazenagem e distribuição de dejetos

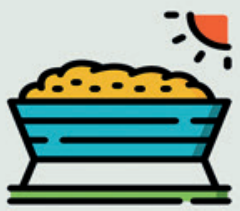

Ração

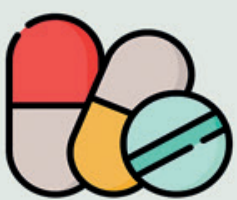

Medicamentos

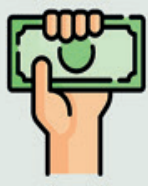

Custos eventuais 


\section{Custos nas diferentes unidades de produção}

Dentro da suinocultura existem 3 tipos principais de produção, são elas:
Unidade Produtora de Leitões (UPL)
Unidade de Terminação (UT)
Unidades de Ciclo Completo (UCT)

\section{UPL - UNIDADE PRODUTORA DE LEITÕES}

A Unidade Produtora de Leitões (UPL) abrange as fases de maternidade que vai até quando os leitões atingem 21 - 28 dias, e fase de creche, que inicia ao desmame e segue até 100 dias, quando os leitões alcançam $27 \mathrm{~kg}$ (aproximadamente).

O produtor que escolhe produzir leitões tem seu lucro determinado pela venda destes animais para produtores que se dedicam em engordá-los, ou seja, para uma unidade de terminação.

$\mathrm{Na}$ UPL, os custos estão associados a:

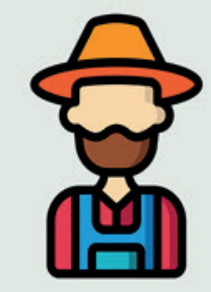

Mão-de-obra

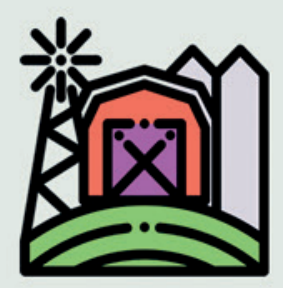

Depreciação de instalações

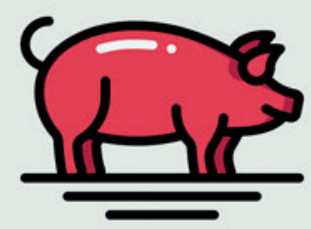

Reposição de reprodutores

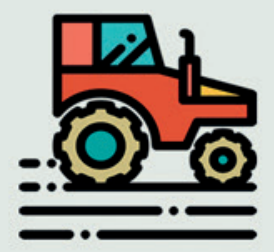

Depreciação de equipamentos

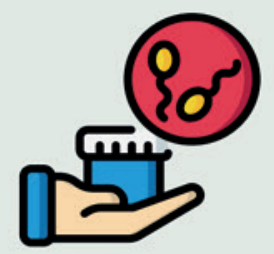

Itens para inseminação

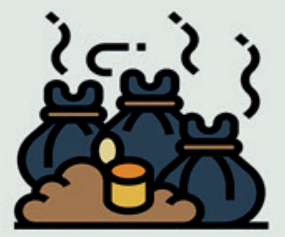

Armazenagem e distribuição de dejetos

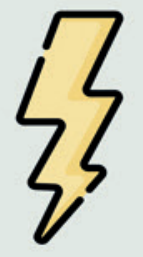

Energia e aquecimento

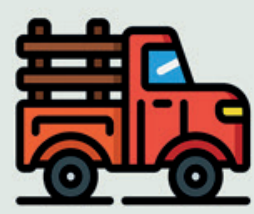

Transporte 


\section{UT - UNIDADE DE TERMINAÇÃO}

A Unidade de Terminação (UT) permanece com os animais por cerca de 52 dias, sendo os animais advindos de uma UPL, sendo responsável pela engorda dos animais, até que atinja o peso de venda ou abate (90-120 kg). Na Unidade de Terminação os custos estão associados:

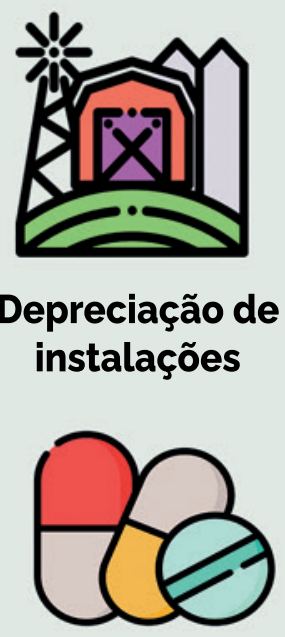

Medicamentos

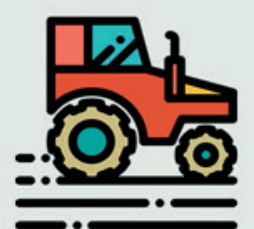

Depreciação de equipamentos

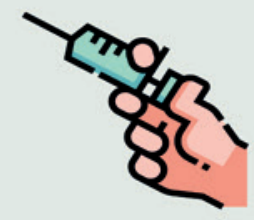

Vacinas

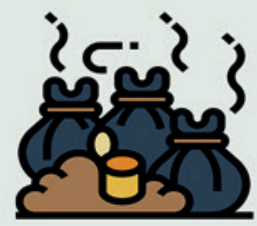

Armazenagem e distribuição de dejetos

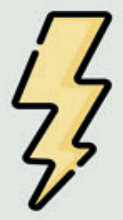

Energia e aquecimento

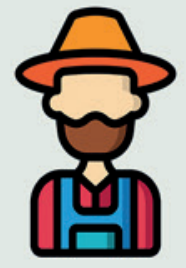

Mão-de-obra

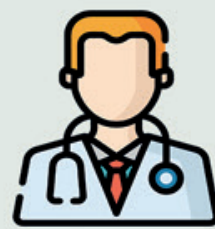

Consultoria médico veterinária

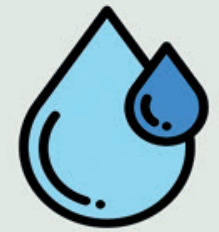

Consumo de água

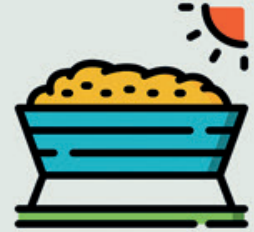

Ração

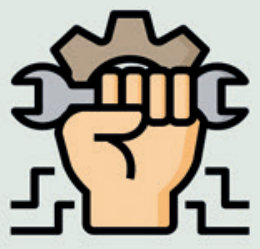

Assistência técnica

O maior custo é a alimentação, já que o objetivo é a engorda dos animais ( $3 \mathrm{Kg} / \mathrm{dia}$ ). 


\section{UCT - UNIDADE DE CICLO COMPLETO}

A Unidade de Ciclo Completo (UCT) abrange todas as fases da suinocultura (maternidade, creche e terminação), tendo o produtor que lidar com todo o processo produtivo. Seus custos podem ser:

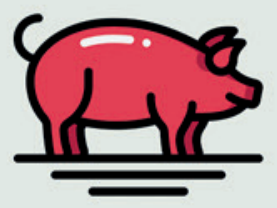

Compra de animais

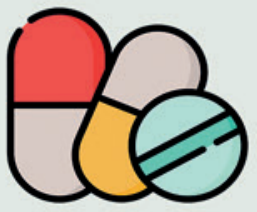

Medicamentos

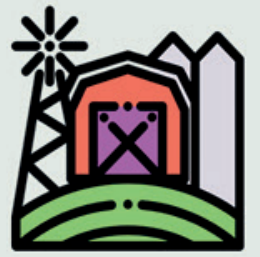

Depreciação de instalações

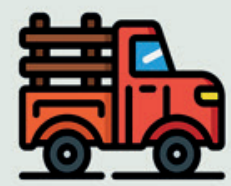

Transporte

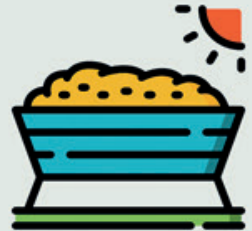

Ração

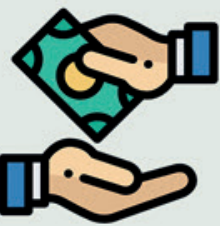

Encargos sociais e trabalhistas

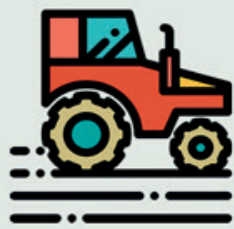

Depreciação de equipamentos

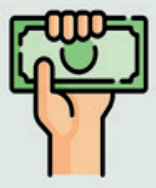

Custos eventuais

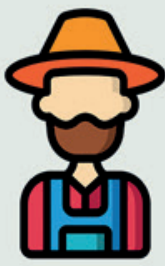

Mão-de-obra

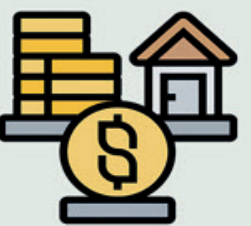

Aluguéis

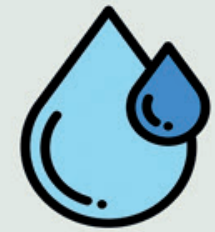

Consumo de água

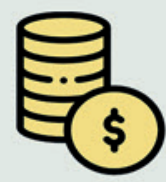

Despesas administrativas

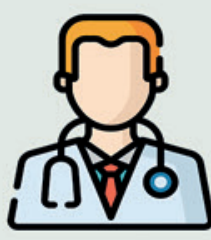

Consultoria médico veterinária

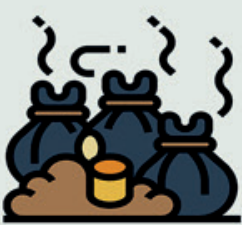

Armazenagem e distribuição de dejetos

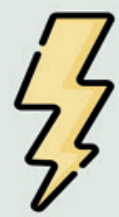

Energia e aquecimento

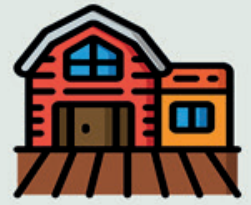

Seguro de prédios e instalações

\section{Exemplo de cálculo da RECEITA TOTAL, CUSTO TOTAL e LUCRO OPERACIONAL}

Se o custo total por animal terminado foi de $\mathrm{R} \$ 5.50$ reais $/ \mathrm{kg}$ e o preço do quilo vendido foi $R \$ 7.50$ reais, temos uma margem líquida de $\mathrm{R} \$ 2,00$ reais por quilo de animal terminado. 
Assim se o produtor vende 50 animais temos uma RECEITA de:

RECEITA TOTAL = quantidade $\times$ peso dos animais $\times$ preço de venda RECEITA TOTAL $=50$ suinos $\times 100 \mathrm{~kg} \times 7,50$ reais RECEITA TOTAL $=37.500$ reais

Se o CUSTO por suíno terminado/engordado foi de 5.50 reais/kg (no ciclo completo, incluindo alimentação, medicamentos, dentre outros), temos que o custo total é:

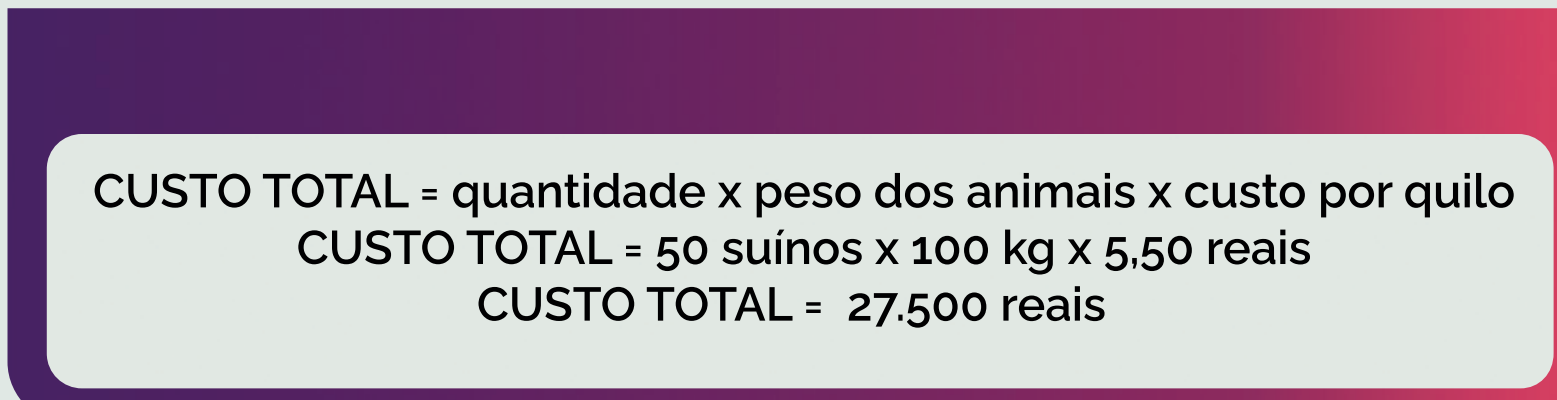

Assim, o LUCRO OPERACIONAL, ou seja, aquele referente a manutenção da operação é:

LUCRO OPERACIONAL = RECEITA TOTAL - CUSTOS TOTAIS LUCRO OPERACIONAL $=37.500$ reais -27.500 reais

LUCRO OPERACIONAL $=10.000$ reais

Desta forma, após pagar os custos envolvidos na produção destes 50 suínos terminados verifica-se um lucro de 10 mil reais.

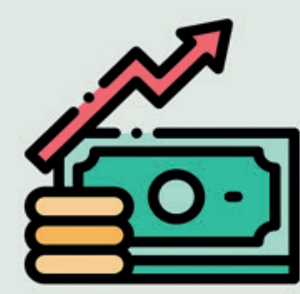

*Ressalta-se que este é um exemplo didático, devendo o produtor calcular o custo, receita e lucro para sua realidade. 


\section{Benchmarking na suinocultura}

A partir dos dados divulgados pela Agriness, do prêmio Melhores da Suinocultura Agriness (2020), tem-se um referencial transparente e confiável para os índices de produção da suinocultura, sendo o maior benchmark da suinocultura na América Latina. Assim, destacamos alguns indices:

\section{BENCHMARKING - SUINOCULTURA}

\begin{tabular}{|c|c|c|c|}
\hline \multirow{2}{*}{ Parâmetro } & \multirow{2}{*}{$\begin{array}{c}\text { iNDICE AGRINESS } \\
2020-\text { BRASIL }\end{array}$} & \multicolumn{2}{|c|}{ PESSOAL } \\
& Ano & Ano \\
\hline Idade da 1 ${ }^{*}$ cobertura (dias) & 232 & & \\
\hline Partos/Fêmea/Ano & 2,4 & & \\
\hline Taxa de Parição (\%) & 87,5 & & \\
\hline Dias não produtivos & 14,4 & & \\
\hline Desmame à Cobertura (dias) & 6,2 & & \\
\hline Ordem de parto das matrizes & 3,7 & & \\
\hline Perdas Reprodutivas (\%) & 12,5 & & \\
\hline Quantidade de Leitões Nascidos Vivos & 13,5 & & \\
\hline Quantidade de Leitões Desmamados & 12,3 & & \\
\hline Leitões desmamados/Fêmea/Ano & 28,9 & & \\
\hline Média de Leitões Nascidos Totais & 14,7 & & \\
\hline Mortes de Leitões na Maternidade (\%) & 8,9 & & \\
\hline Peso de Nascimento do Leitão (kg) & 1,4 & & \\
\hline Leitões Natimortos e Mortos ao Nascer (\%) & 6,1 & & \\
\hline Leitões Mumificados (\%) & 2,2 & & \\
\hline
\end{tabular}

-Dados completos e disponiveis em:

https://comunicacao-agriness.s3-sa-east-1.amazonaws.com/relatorio_melhores_web_edicao13.pdf 
$\leftrightarrow$

Dि जि

[O 
Tabela para acompanhamento de ocorrências

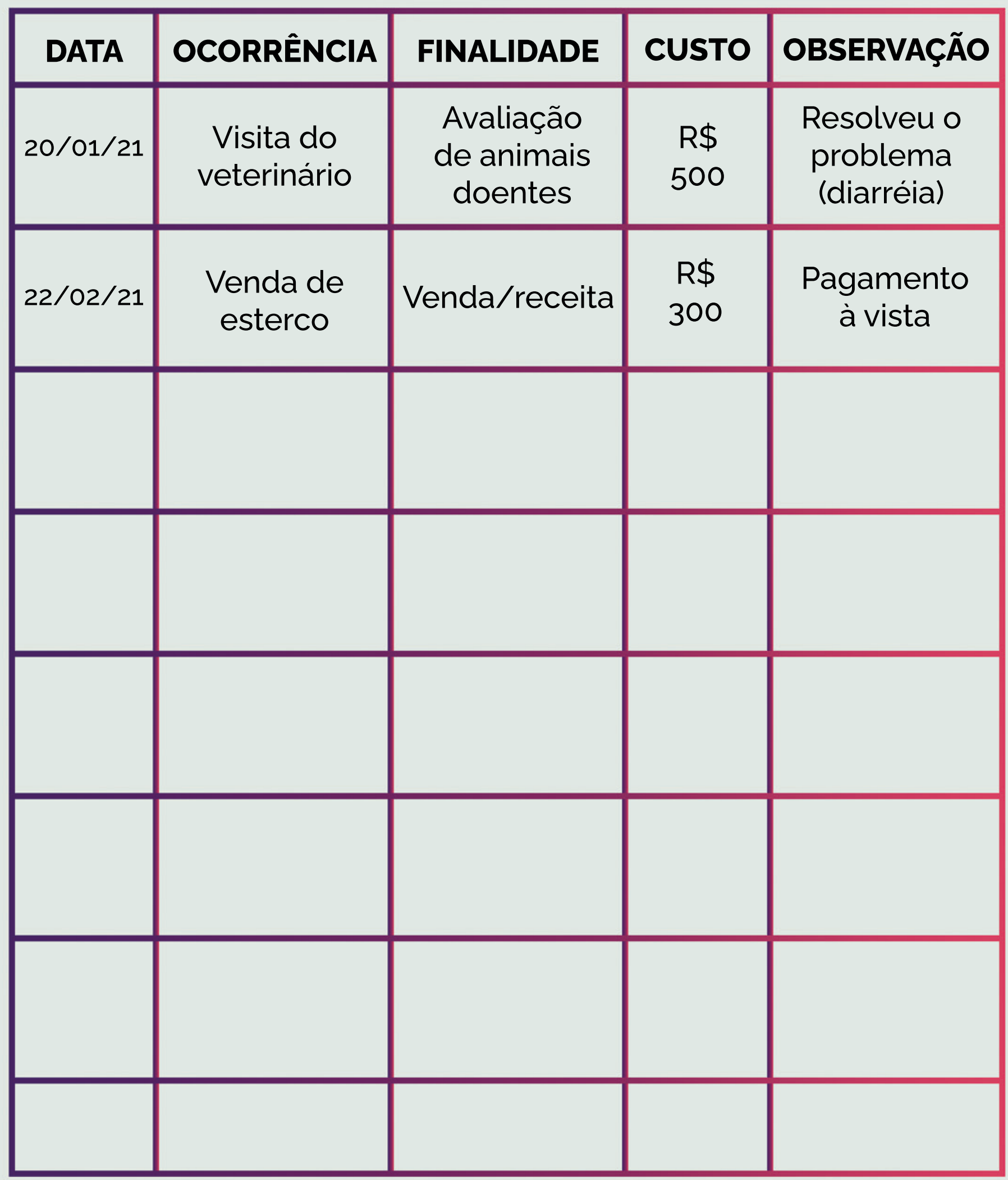




\section{Referências bibliográficas}

\section{CUSTOS: INIMIGOS OU ALIADOS?}

CONAB. Custos de produção agrícola: a metodologia da Conab. Brasilia. 60 p. Disponivel em: http://www.conab.gov.br/conabweb/download/safra/custos.pdf.

KAY, R.D.; EDWARDS, W.M.; DUFFY, P.A. Gestão de propriedades rurais. 7 ed. Porto Alegre: AMGH, 2014.

PINTO, A.A.G.; LIMEIRA, A.L.F.; SILVA, C.A.S.; COELHO, F.S. Gestão de custos. 4 ed. São Paulo: FGV Editora, 2018.

\section{AVICULTURA}

Notícias Agrícolas - Disponivel em : https://www.noticiasagricolas.com.br/cotacoes/frango. Acesso em: 20/09/2020.

CEPEA - Centro de Estudos Avançados em Economia Aplicada. Disponivel em: https://cepea.esalq.usp.br/br/indicador/frango.aspx. Acesso em: 20/09/2020.

EMBRAPA (ICP) - Empresa Brasileira de Pesquisa Agropecuária. Disponivel em: https://www.embrapa.br/suinos-e-aves/cias. Acesso em: 20 de setembro de 2020.

EMBRAPA - Empresa Brasileira de Pesquisa Agropecuária. Disponivel em: https://www.embrapa.br/busca-de-noticias/-/noti-

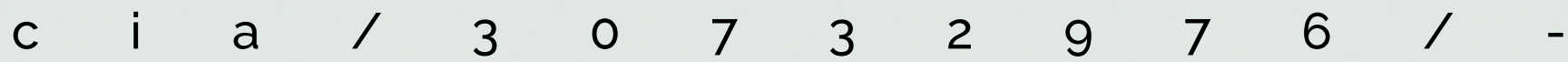
custos-de-producao-de-suinos-e-de-frangos-de-corte-voltam-a -subir-em-novembro. Acesso em: 20/09/2020.

\section{BOVINOCULTURA}

CAGED - Cadastro Geral de Empregados e Desempregados. Disponivel em: http://portalfat.mte.gov.br/programas-e-acoes-2/caged-3/. Acesso em: 09/10/2020. 


\section{SUINOCULTURA}

EMBRAPA (ICP), embrapa, 2019. Página inicial. Disponível em:<https://www.embrapa.br/suinos-e-aves/cias>. Acesso em: 25 de agosto de 2020.

AGRINESS. Relatório Anual do Desempenho da Produção de Suinos. Disponivel em: <https://comunicacao-agrin es s. s 3-s a - e a s t-1. a m a zon aws.com/relatorio_melhores_web_edicao13.pdf> Acesso em: 18 de maio de 2020.

AGRINESS. Relatório Melhores Suinocultura, 2019. Disponivel em <relatorio_melhores_suinocultura_agriness12ed-2019.pdf $>$. Acesso em: 30 de agosto de 2020.

ANTONIO, Rony F. Manual prático da suinocultura. Aprenda Fácil, 2012.

FERREIRA, Adilson hélio. et al. Produção de Suinos: Teoria e Prática. Brasilia: ABCS, 24 de jul de 2014.

Ronald D. Kay; William M. Edwards; Patricia A. Duffy. Gestão de Propriedades Rurais. McGraw-Hill, 2014.

TAMLAMINI, Dirceu João D.; MARTINS, Franco Muller; ARBOIT, Clênio; WOLOZSIM, Nilson. Custos agregados da produção integrada de suínos nas fases de leitões e de terminação, 2006. Disponivel em<http://www.custoseagronegocioonline.com.br/especialv2/custos\%20agregados\%20de\%20producao.pdf>. Acesso em: 20 de agosto de 2020.

PONTES, Elisangela de Fátima R.; CAMARGO, Jessyca R.; NETO, Azior de Souza; MAZUREK, Gilmar Batista. Custos na produção de suínos: um estudo de caso, 2009. Disponivel em:<http://www.custoseagronegocioonline.com.br/numero1v5/suinocultura.pdf $>$. Acesso em: 20 de agosto de 2020.

\section{Fontes gráficas}

www.unsplash.com

www.pixabay.com

www.flaticon.com (Freepik e Smashicon) 


\title{
Realização
}

\section{GRUPO CORES E VALORES - UECE}

\author{
Aderson M. Viana Neto \\ Julyanna C. Maciel \\ Lais D. Ferreira \\ Roberta R. Furtado
}

Samuel Victor de A. Veras 
EDITORA
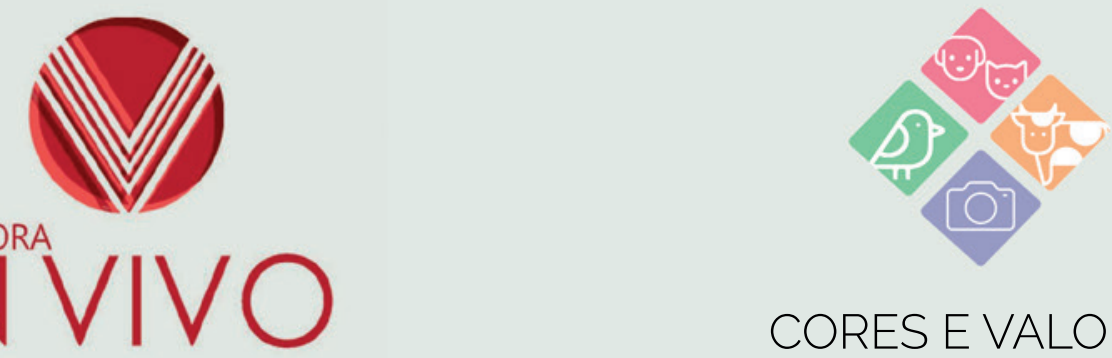

CORES E VALORES 